NISTIR 90-3938

\title{
MEASUREMENT OF \\ ELECTRIC FIELD STRENGTH \\ NEAR HIGHER POWERED \\ PERSONAL TRANSCEIVERS
}

John Adams

Doris Wu

Alan Budlong

$Q C$

100

.056

90-3938

1990

C. 2 
NATIONAL INSTTTUTE OF STANDARDS \&

TECHNOLOGY

Research Information Center

Gaithersourg, MD 20899

DATE DUE

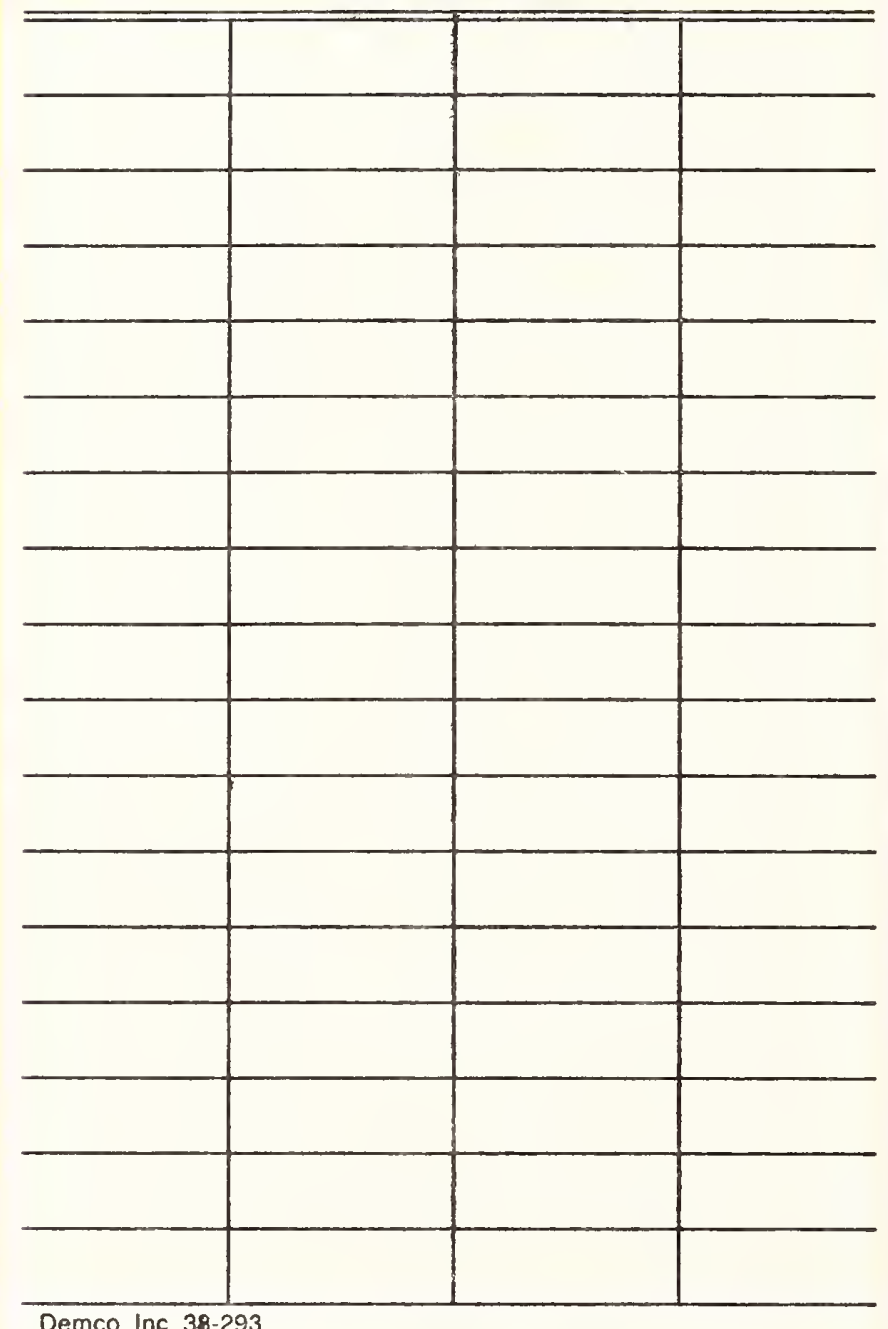

Demco, Inc. 38-293 


\section{NISTIR 90-3938}

\section{MEASUREMENT OF \\ ELECTRIC FIELD STRENGTH \\ NEAR HIGHER POWERED \\ PERSONAL TRANSCEIVERS}

John Adams

Doris Wu

Alan Budlong

Electromagnetic Fields Division

Center for Electronics and Electrical Engineering

National Engineering Laboratory

National Institute of Standards and Technology

Boulder, Colorado 80303-3328

May 1990

Sponsored by

Law Enforcement Standards Laboratory

National Institute of Standards and Technology

Gaithersburg, Maryland 20899

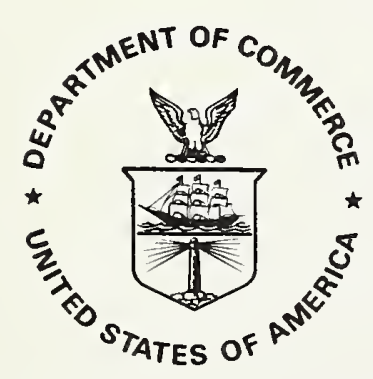

U.S. DEPARTMENT OF COMMERCE, Robert A. Mosbacher, Secretary NATIONAL INSTITUTE OF STANDARDS AND TECHNOLOGY, John W. Lyons, Director 



\section{CONTENTS}

Page

1

INTRODUCTION. ......................... 1

2

FIELD STRENGTH MEASUREMENTS................ 2

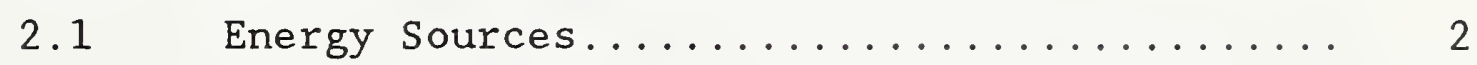

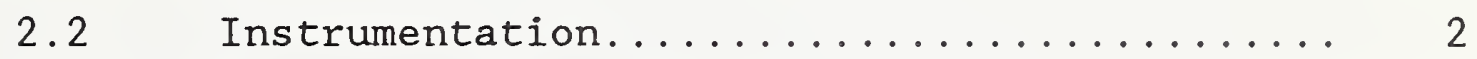

2.3 Test Facilities.................. 3

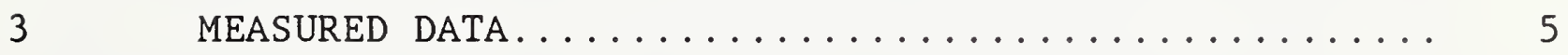

4 COMPARISON OF MEASURED DATA WITH THE ANSI C95.1-1982

STANDARD AND CONCLUSIONS ................ 6

REFERENCES ............................. 7 


\section{LIST OF FIGURES}

Figure

Page

1 Non-metallic support structure for array of 10 probes ..........8

2 Complete support structure used in anechoic chamber ........... 9

3 Rotation of personal transceivers ..................... 10

4 Illustration of method of keying transceiver using pneumatic

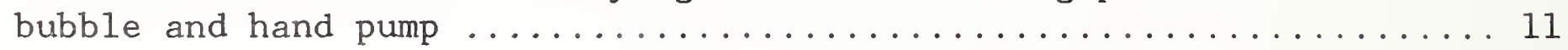

5 Setup for measurements on ground screen $\ldots \ldots \ldots \ldots \ldots \ldots \ldots \ldots \ldots$

6 Picture of setup for measurements inside anechoic chamber ....... 13

7 Picture of setup for measurements on ground screen. Note black plastic cover over probe array to block sunlight .......... 14

8 Display of magnitude and $\mathrm{x}, \mathrm{y}$ and $\mathrm{z}$ components of the electric field distribution of probe \#4 (figure 8a), probe \#6 (figure 8b), and probe \#8 (figure 8c), all at a distance of $12 \mathrm{~cm}$ from

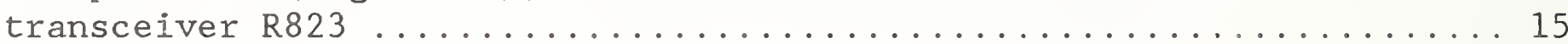

9 Plot of electric field around transceiver F40 (40 $\mathrm{MHz}$ ) at a separation distance of $7 \mathrm{~cm}$. Fields detected by 9 probes are shown as a function of angle of rotation $\ldots \ldots \ldots \ldots \ldots \ldots$

10 Plot of electric field around transceiver F40 (40 $\mathrm{MHz}$ ) at a separation distance of $12 \mathrm{~cm}$. Fields detected by 9 probes are shown as a function of angle of rotation $\ldots \ldots \ldots \ldots \ldots \ldots \ldots \ldots$

11 Plot of electric field around transceiver D40 (40 $\mathrm{MHz}$ ) at a separation distance of $7 \mathrm{~cm}$. Fields detected by 9 probes are shown as a function of angle of rotation $\ldots \ldots \ldots \ldots \ldots \ldots \ldots$

12 Plot of electric field around transceiver $\mathrm{D} 40$ (40 $\mathrm{MHz}$ ) at a separation distance of $12 \mathrm{~cm}$. Fields detected by 9 probes are shown as a function of angle of rotation .................. 19

13 Plot of electric field around transceiver E162 (162 $\mathrm{MHz}$ ) at a separation distance of $7 \mathrm{~cm}$. Fields detected by 9 probes are shown as a function of angle of rotation .................. 20

14 Plot of electric field around transceiver E162 (162 MHz) at a separation distance of $12 \mathrm{~cm}$. Fields detected by 9 probes are shown as a function of angle of rotation $\ldots \ldots \ldots \ldots \ldots \ldots \ldots \ldots \ldots$

15 Plot of electric field around transceiver D162 (162 MHz) at a separation distance of $7 \mathrm{~cm}$. Fields detected by 9 probes are shown as a function of angle of rotation $\ldots \ldots \ldots \ldots \ldots \ldots \ldots \ldots \ldots \ldots$ 


\section{LIST OF FIGURES (contd.)}

Figure

16 Plot of electric field around transceiver D162 (162 MHz) at a separation distance of $12 \mathrm{~cm}$. Fields detected by 9 probes are shown as a function of angle of rotation $\ldots \ldots \ldots \ldots \ldots \ldots \ldots \ldots$

17 Plot of electric field around transceiver 6464 (464 MHz) at a separation distance of $7 \mathrm{~cm}$. Fields detected by 9 probes are shown as a function of angle of rotation. Effects of discharging and recharging battery may be seen ............... 24

18 Plot of electric field around transceiver 6464 (464 MHz) at a separation distance of $12 \mathrm{~cm}$. Fields detected by 9 probes are shown as a function of angle of rotation. Effects of discharging and recharging battery may be seen $\ldots \ldots \ldots \ldots \ldots \ldots$

19 Plot of electric field around transceiver $\mathrm{B} 464$ (464 $\mathrm{MHz}$ ) at a separation distance of $7 \mathrm{~cm}$. Fields detected by 9 probes are shown as a function of angle of rotation $\ldots \ldots \ldots \ldots \ldots \ldots \ldots$

20 Plot of electric field around transceiver $\mathrm{B} 464$ (464 $\mathrm{MHz}$ ) at a separation distance of $12 \mathrm{~cm}$. Fields detected by 9 probes are shown as a function of angle of rotation .................... 27

21 Plot of electric field around transceiver A823 ( $823 \mathrm{MHz}$ ) at a separation distance of $7 \mathrm{~cm}$. Fields detected by 9 probes are shown as a function of angle of rotation $\ldots \ldots \ldots \ldots \ldots \ldots \ldots \ldots$

22 Plot of electric field around transceiver $\mathrm{A} 823$ (823 $\mathrm{MHz}$ ) at a separation distance of $12 \mathrm{~cm}$. Fields detected by 9 probes are

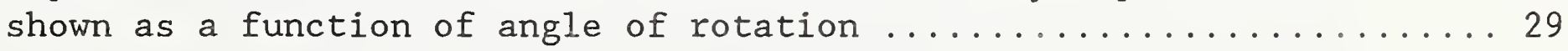

23 Plot of electric field around transceiver 8823 (823 $\mathrm{MHz}$ ) at a separation distance of $7 \mathrm{~cm}$. Fields detected by 9 probes are shown as a function of angle of rotation. Effects of discharging and recharging battery may be seen $\ldots \ldots \ldots \ldots \ldots$

24 Plot of electric field around transceiver B823 ( $823 \mathrm{MHz}$ ) at a separation distance of $12 \mathrm{~cm}$. Fields detected by 9 probes are shown as a function of angle of rotation. Effects of discharging and recharging battery may be seen $\ldots \ldots \ldots \ldots \ldots \ldots \ldots$

25 Three-dimensional plot of magnitude of electric field around transceiver $F 40$ ( $40 \mathrm{MHz})$. Radii of disks are proportional to magnitude of electric field. Separation distance between transceiver antenna and probes is in centimeters (RADIUS $=7$ ). Maximum value of field strength is marked with black dot. The two numbers after MAXIMUM POINT are electric field strength in volts per meter and angle of rotation in degrees 


\section{LIST OF FIGURES (contd.)}

Figure

26 Three-dimensional plot of magnitude of electric field around transceiver $F 40(40 \mathrm{MHz})$. Radii of disks are proportional to magnitude of electric field. Separation distance between transceiver antenna and probes is in centimeters (RADIUS $=12$ ). Maximum value of field strength is marked with black dot. The two numbers after MAXIMUM POINT are electric field strength in volts per meter and angle of rotation in degrees.............. 33

27 Three-dimensional plot of magnitude of electric field around transceiver D40 (40 $\mathrm{MHz})$. Radii of disks are proportional to magnitude of electric field. Separation distance between transceiver antenna and probes is in centimeters (RADIUS $=7$ ). Maximum value of field strength is marked with black dot. The two numbers after MAXIMUM POINT are electric field strength in volts per meter and angle of rotation in degrees ............. 34

28 Three-dimensional plot of magnitude of electric field around transceiver $\mathrm{D} 40(40 \mathrm{MHz})$. Radii of disks are proportional to magnitude of electric field. Separation distance between transceiver antenna and probes is in centimeters (RADIUS $=12$ ). Maximum value of field strength is marked with black dot. The two numbers after MAXIMUM POINT are electric field strength in volts per meter and angle of rotation in degrees ................. 35

29 Three-dimensional plot of magnitude of electric field around transceiver E162 (162 $\mathrm{MHz}$ ). Radii of disks are proportional to magnitude of electric field. Separation distance between transceiver antenna and probes is in centimeters (RADIUS $=7$ ). Maximum value of field strength is marked with black dot. The two numbers after MAXIMUM POINT are electric field strength in volts per meter and angle of rotation in degrees ............. 36

30 Three-dimensional plot of magnitude of electric field around transceiver E162 (162 MHz). Radii of disks are proportional to magnitude of electric field. Separation distance between transceiver antenna and probes is in centimeters (RADIUS $=12$ ). Maximum value of field strength is marked with black dot. The two numbers after MAXIMUM POINT are electric field strength in volts per meter and angle of rotation in degrees ............ 37

31 Three-dimensional plot of magnitude of electric field around transceiver D162 (162 MHz). Radii of disks are proportional to magnitude of electric field. Separation distance between transceiver antenna and probes is in centimeters (RADIUS $=7$ ). Maximum value of field strength is marked with black dot. The two numbers after MAXIMUM POINT are electric field strength in volts per meter and angle of rotation in degrees ........... 38 


\section{LIST OF FIGURES (contd.)}

Figure

32 Three-dimensional plot of magnitude of electric field around transceiver D162 (162 MHz). Radii of disks are proportional to magnitude of electric field. Separation distance between transceiver antenna and probes is in centimeters (RADIUS $=12$ ). Maximum value of field strength is marked with black dot. The two numbers after MAXIMUM POINT are electric field strength in volts per meter and angle of rotation in degrees .............39

33 Three-dimensional plot of magnitude of electric field around transceiver $6464(464 \mathrm{MHz})$. Radii of disks are proportional to magnitude of electric field. Separation distance between transceiver antenna and probes is in centimeters (RADIUS $=7$ ). Maximum value of field strength is marked with black dot. The two numbers after MAXIMUM POINT are electric field strength in volts per meter and angle of rotation in degrees ...........40

34 Three-dimensional plot of magnitude of electric field around transceiver $\mathrm{C} 464(464 \mathrm{MHz})$. Radii of disks are proportional to magnitude of electric field. Separation distance between transceiver antenna and probes is in centimeters (RADIUS $=12$ ). Maximum value of field strength is marked with black dot. The two numbers after MAXIMUM POINT are electric field strength in volts per meter and angle of rotation in degrees .......41

35 Three-dimensional plot of magnitude of electric field around transceiver $\mathrm{C} 464$ ( $464 \mathrm{MHz}$ ) measured on ground screen - - compare with figure 28 which was measured in anechoic chamber. Radii of disks are proportional to magnitude of electric field. Separation distance between transceiver antenna and probes is in centimeters (RADIUS $=12$ ). Maximum value of field strength is marked with black dot. The two numbers after MAXIMUM POINT are electric field strength in volts per meter

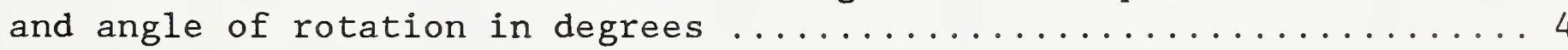

36 Three-dimensional plot of magnitude of electric field around transceiver B464 (464 MHz). Radii of disks are proportional to magnitude of electric field. Separation distance between transceiver antenna and probes is in centimeters (RADIUS $=7$ ). Maximum value of field strength is marked with black dot. The two numbers after MAXIMUM POINT are electric field strength in volts per meter and angle of rotation in degrees ............4

37 Three-dimensional plot of magnitude of electric field around transceiver $\mathrm{B} 464(464 \mathrm{MHz})$. Radii of disks are proportional to magnitude of electric field. Separation distance between transceiver antenna and probes is in centimeters (RADIUS $=12$ ). Maximum value of field strength is marked with black dot. The two numbers after MAXIMUM POINT are electric field strength in volts per meter and angle of rotation in degrees . . . . . . . . . 44 


\section{LIST OF FIGURES (contd.)}

Figure

Page

38 Three-dimensional plot of magnitude of electric field around transceiver A823 ( $823 \mathrm{MHz}$ ). Radii of disks are proportional to magnitude of electric field. Separation distance between transceiver antenna and probes is in centimeters (RADIUS $=7$ ). Maximum value of field strength is marked with black dot. The two numbers after MAXIMUM POINT are electric field strength in volts per meter and angle of rotation in degrees ...........4

39 Three-dimensional plot of magnitude of electric field around transceiver A823 (823 MHz). Radii of disks are proportional to magnitude of electric field. Separation distance between transceiver antenna and probes is in centimeters (RADIUS $=12$ ). Maximum value of field strength is marked with black dot. The two numbers after MAXIMUM POINT are electric field strength in volts per meter and angle of rotation in degrees . . . . . . . . . 46

40 Three-dimensional plot of magnitude of electric field around transceiver B823 (823 MHz). Radii of disks are proportional to magnitude of electric field. Separation distance between transceiver antenna and probes is in centimeters (RADIUS $=7$ ). Maximum value of field strength is marked with black dot. The two numbers after MAXIMUM POINT are electric field strength

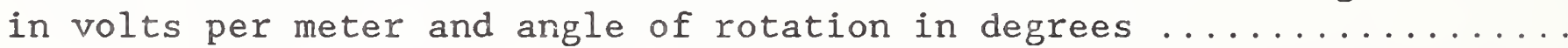

41 Three-dimensional plot of magnitude of electric field around transceiver B823 ( $823 \mathrm{MHz}$ ). Radii of disks are proportional to magnitude of electric field. Separation distance between transceiver antenna and probes is in centimeters (RADIUS = 12). Maximum value of field strength is marked with black dot. The two numbers after MAXIMUM POINT are electric field strength in volts per meter and angle of rotation in degrees ...........48

42 Comparison of maximum measured values of electric field strength with limit from ANSI C95.1-1982, Safety Levels with Respect to Human Exposure to Radio Frequency Electromagnetic Fields ............

43 Comparison of the square of E field (proportional to power density) calculated from maximum measured values of electric field strength with limit from ANSI C95.1-1982, Safety Levels with Respect to Human Exposure to Radio Frequency Electromagnetic Fields .......... 50 
Measurement of Electric Field Strength

Near Higher Powered Personal Transceivers

John Adams, Doris Wu, and Allen Budlong

Electric field strengths were measured at a number of points near 5-W personal transceivers. The points were located on cylinders of revolution around the antenna with radii of 7 , $9.5,12,14.5,17$, and, in some cases, 27, 37, and $47 \mathrm{~cm}$. At shotter distances, these measured values exceeded the exposure limits suggested in ANSI Standard C95.1-1982.

Key words: electric field measurements; personal transceivers; walkie-talkies.

\section{INTRJDUCTION}

Law enforcement and other public safety personnel use various types of communication equipment in the performance of their day-to-day activities. Since the inception of Federal funding in the early 1970s, many law enforcement agencies have substantially increased the number of handheld personal transceivers used in their departments. A decade ago, most of these radios generated between 1 and $2 \mathrm{~W}$ of output power. In the past few years, however, many agencies are purchasing transceivers that produce as much as 5 or $6 \mathrm{~W}$ of output power as a means of improving communication range and system reliability. Unfortunately, a by-product of this enhanced capability is an increase of field strengths in the vicinity of the transceiver and its antenna.

Because of concern regarding the electromagnetic environment in which law enforcement personnel must work, the Technology Assessment Program Advisory Council recommended the initiation of a study to characterize this environment at the frequency bands used by police. The first phase of the measurement program produced a report on field strengths in vehicles with communications transmitters [1]. This effort was primarily directed toward measuring the fields produced by mobile transceivers used in vehicles. The 
second phase of this effort, reported in this document, is concerned with the field strengths produced by higher powered, handheld transceivers. This report contains the results of tests conducted on typical transceivers in the four frequency bands used by the law enforcement community: 30-50, 150174, 400-520, and 806-866 MHz. The fields were measured at distances likely to be encountered in practice.

\section{FIELD STRENGTH MEASUREMENTS}

\section{$2.1 \quad$ Energy Sources}

During this measurement series, personal transceivers were used that operated at frequencies of $40.27,162.475,464$ and $823 \mathrm{MHz}$ and with approximate output powers of $5,5,5$, and $3 \mathrm{~W}$, respectively. Electric field strengths were measured at locations described by cylinders of increasing radii with the antenna of the transceiver at the center of the cylinder.

\subsection{Instrumentation}

The electric field strength was measured with the multisensor, automated electric field strength measurement system described in NBSIR 86 3056 [2]. This multisensor system consists of 10 probes. Each probe has three dipoles; each dipole feeds a single channel which can be used to measure the $\mathrm{x}, \mathrm{y}$, or $\mathrm{z}$ components of the electric field. RF energy is converted to dc voltage by a diode detector at each dipole. Data from each channel were then stored in a file using a computer system and the software described in NBSIR 86-3056 [2]. The data were then converted into volts per meter with a calibration factor correction applied for each specific frequency. The $\mathrm{x}, \mathrm{y}$, and $\mathrm{z}$ components of the electric field for each probe and also the magnitude, $|E|=\sqrt{E_{x}^{2}}+E_{y}^{2}+E_{z}^{2}$, were recorded in units of volts per meter vs degrees of rotation of the transceiver.

A support structure shown in figure 1 held the probes in a vertical array with a separation of $10 \mathrm{~cm}$ between each probe. The support structure was built of nonmetallic material so as to minimize reflections. Probe \#1 was at the bottom of the array while probe \#10 was at the top. The complete support structure is shown in figure 2. 
The probe array could be repositioned horizontally to change separation distance. It could also be repositioned vertically by $5 \mathrm{~cm}$ to increase the number of measurement points from 10 to 20. The vertical position is indicated by the term "offset" in some figures. Vertical adjustment was also used to obtain a common reference point for each of the personal transceivers. This reference point was determined by placing the base of the antenna on the transceiver at the same height as the probe \#5. All the personal transceivers had different antenna lengths and body dimensions .

The measurements were made with the probe array held stationary at one of several separation distances while the personal transceiver was rotated in increments as shown in figure 3. Rotation was in a clockwise direction as seen from above with the $0^{\circ}$ point on the short side of the transceiver case toward the probe array. The size of the rotation increment was a compromise between stepping speed and battery discharge rate.

In order to key the transceiver on, a pneumatic switch was improvised as shown in figure 4. It consisted of a rubber bulb taped and strapped to the push-to-talk switch. This switch was linked by a length of plastic tube to a hand-operated air pump. As the pump was actuated, the air bubble attached to the personal transceiver expanded, and turned on the transmitter. The personal transceivers were never left on for more than 45 seconds, since there was a noticeable decrease in the electric field as the battery discharged and the output stage heated. After each rotation of $360^{\circ}$ the transceiver batteries were recharged so that each rotation had the same battery charge as the previous one.

\subsection{Test Facilities}

The measurements were made using either of two facilities depending on the frequency of the transceiver. For transceivers operating at 464 and $823 \mathrm{MHz}$, measurements were made in an anechoic chamber. The measurements were fully automated, since the chamber is equipped with a five-axis positioner that allowed rotation of the personal transceiver $360^{\circ}$ in $3.6^{\circ}$ or $7.2^{\circ}$ steps as shown in figure 3. This allowed for 100 or 50 data points, respectively. The personal transceiver was supported above the rotator by a long fiberglass tube. The top of the tube had a wooden platform to support 
the personal transceiver while the bottom was attached to the rotator. The wooden table was covered with anechoic material to reduce reflections. The probe structure was also supported by a wooden table.

Horizontal separation distances of $7,9.5,12,14.5,17,27,37,47$, $57 \mathrm{~cm}$ were used. The smaller increments at smaller separation distances were necessary to show the more rapid spatial variations in field strengths close to the transceiver. However, at the 7 and $9.5 \mathrm{~cm}$ distances, the side of the transceiver case would hit the array of probes between approximately $135^{\circ}$ and $225^{\circ}$ of rotation, so no values could be recorded within those limits (See figure 3).

For transceivers operating at 40.27 or $162.475 \mathrm{MHz}$, measurements were made on an outdoor ground screen, since the absorber in the anechoic room is not effective at these lower frequencies. The measurements on the ground screen were not automated and therefore took more time; only 16 steps of rotation could be used before the battery charge was reduced below an acceptable level. All the rotations were done by hand in $22.5^{\circ}$ steps as shown in figure 5. The rotation was accomplished by rotating a fiberglass support tube from a tunnel under the ground screen. An additional tube was attached to the support tube to allow this rotation and to indicate the azimuth.

Because the probes were sensitive to sunlight, the probe fixture had to be wrapped in black plastic. The probes were not affected by moderate changes in temperature. At the lower frequencies fewer increments of separation distance were used, and offsets in elevation were also omitted since the spatial variations in field strength are not as rapid at the longer wavelengths. Figure 6 is a photograph of the setup in the anechoic chamber. Figure 7 is a photograph of the setup on the groundscreen.

The probes were calibrated and have an uncertainty of $\pm 1 \mathrm{~dB}$ in field strength. All values reported have this as a basic uncertainty. The values measured on the ground screen, where the positioning uncertainty was $\pm 1 \mathrm{~cm}$, have the same basic uncertainty, but the values may not have been measured at exactly the position reported. At $40 \mathrm{MHz}$, this causes an additional \pm 4 $\mathrm{dB}$ uncertainty; at $162 \mathrm{MHz}$, an additional $\pm 3 \mathrm{~dB}$ uncertainty. Positioning 
errors in the anechoic chamber were very small, less than $\pm 1 \mathrm{~mm}$; this causes an additional $\pm 0.25 \mathrm{~dB}$ uncertainty.

An operator's hand and arm may cause increase of field strengths during actual use of a transceiver over those measured when the transceiver was supported by a plastic structure. This is due to the increase in effective size of ground screen for the monopole antenna of the transceiver. This effect was about +3 to $+4 \mathrm{~dB}$ in limited cases, but was not thoroughly investigated.

\section{MEASURED DATA}

For each of the transceivers measured in the anechoic chamber, 25500 data points were recorded, and from these, 8500 data points for the magnitude of $E$ were calculated. Only 336 data points were recorded for a transceiver measured on the ground plane.

All measured values of the $x, y$, and $z$ components of the electric field are available, along with calculated values of magnitude, on a DoSformatted disk if anyone should want to calculate coupled energy based on boundary conditions. Figures $8 \mathrm{a}, 8 \mathrm{~b}$, and $8 \mathrm{c}$ illustrate this depth of detail of information. $\mathrm{E}_{\mathrm{y}}$ is the vertical component of electric field.

The magnitude of the E field is the quantity used in the next set of figures, 9-24. The data are displayed in two-dimensional plots for each transceiver at the shortest separation, $7 \mathrm{~cm}$, and at a distance of $12 \mathrm{~cm}$, the shortest distance which allowed a full $360^{\circ}$ rotation of the transceiver. The horizontal axis is the angle of rotation. The $7 \mathrm{~cm}$ separation shows maximum field strengths. Some problems that occurred during data gathering (such as variation due to varying battery voltage) show up in some of these figures. Vertical displacement is indicated by the term offset.

Figures 25 through 41 are three-dimensional plots in cylindrical coordinates; they show the spatial variations in field strength around the antenna of the transceiver. The radii of the disks are proportional to measured field strengths; the highest field strengths occur in the volume immediately adjacent to the transceiver antenna. There are no nulls or low field strengths in the immediate vicinity of the transceiver antenna. 
It is not within the scope of this study to state what levels of electromagnetic fields constitute a health hazard. Such issues are outside the mission and expertise of the National Institute of Standards and Technology (NIST) and are the responsibility of organizations and committees that have been established to perform and interpret research on the biological effects of electromagnetic fields and to set exposure limits based on the results of such research. NIST is responsible for the accurate measurement of electromagnetic fields.

The American National Standards Institute (ANSI), together with the Institute of Electrical and Electronic Engineers (IEEE) and the US Department of the Navy, have prepared and adopted a voluntary radio frequency protection guide for the frequency bands involved in this measurement program. This guide was published as ANSI C95.1-1982, Safety Levels with Respect to Human Exposure to Radio Frequency Electromagnetic Fields, $300 \mathrm{kHz}$ to $100 \mathrm{GHz}$ [3]. It was reviewed and approved by the 35 organizations and government agencies listed on page 4 in the standard.

This ANSI standard gives limits in units of field strength squared $(\mathrm{V} / \mathrm{m})^{2}$ for electric field strength, $(\mathrm{A} / \mathrm{m})^{2}$ for magnetic field strength), and $\mathrm{mW} / \mathrm{cm}^{2}$ for power density as a function of frequency. These limits were selected to keep the specific absorption rate (SAR) below $0.40 \mathrm{~W} / \mathrm{kg}$ of human tissue as averaged over the whole body and the SAR below $8 \mathrm{~W} / \mathrm{kg}$ averaged over any $1 \mathrm{~g}$ of tissue. Values are given in table 1 and shown graphically in Figure $A 1$ of the standard.

The presentation format that is probably of most interest to the user of these transceivers is a graph of typical measured field strengths plotted relative to the field strength limit for human exposure to radiofrequency fields as given in the ANSI C95.1-1982 Standard [3]. There are many temporal and spatial variations allowed by this standard, but these measured data show that the field strengths are clearly greater than the recommended levels. At 40 and $162 \mathrm{MHz}, \mathrm{E}^{2}$ is about two orders of magnitude greater than the value specified in this standard. See figures 42 and 43 . 
Although the measured values of field strength from these transceivers are high relative to the exposure limits of the ANSI standard, how much energy couples into the body is not really known. What is needed is a more thorough analysis of the coupling of electromagnetic energy into a phantom of a human head, with particular emphasis on coupling into the eyes, which are usually very near the strongest fields measured, near the antenna of the transceiver. The eyes are one of the more vulnerable organs of the human body because the poor capacity of the circulatory system within the eyes is inefficient at removing heat.

\section{REFERENCES}

[1] J.F. Shafer, Field Strength Levels in Vehicles Resulting from Communication Transmitters, NIJ Report 200-83, National Institute of Justice, U.S. Department of Justice, Washington, DC 20531, June 1984.

[2] W.D. Bensema, G.H. Koepke, and H.W. Medley, Handbook for Operation and Maintenance of an NBS Multisensor Automated EM Field Measurement System, NBSIR 86-3056, Oct. 1986.

[3] Safety Levels with Respect to Human Exposure to Radio Frequency Electromagnetic Fields, $300 \mathrm{kHz}$ to $100 \mathrm{GHz}$, American National Standards Institute, ANSI C95.1-1982. 


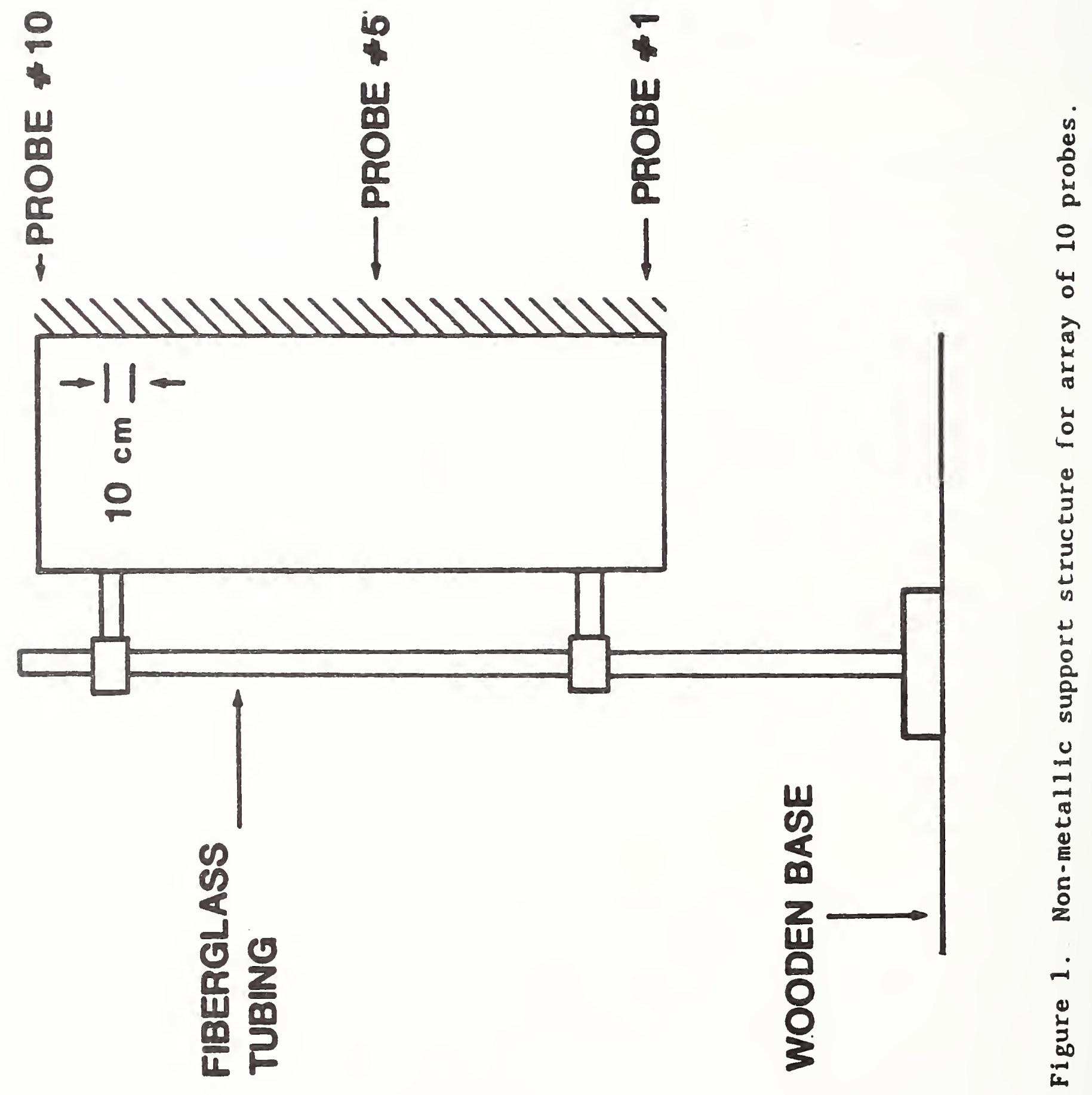




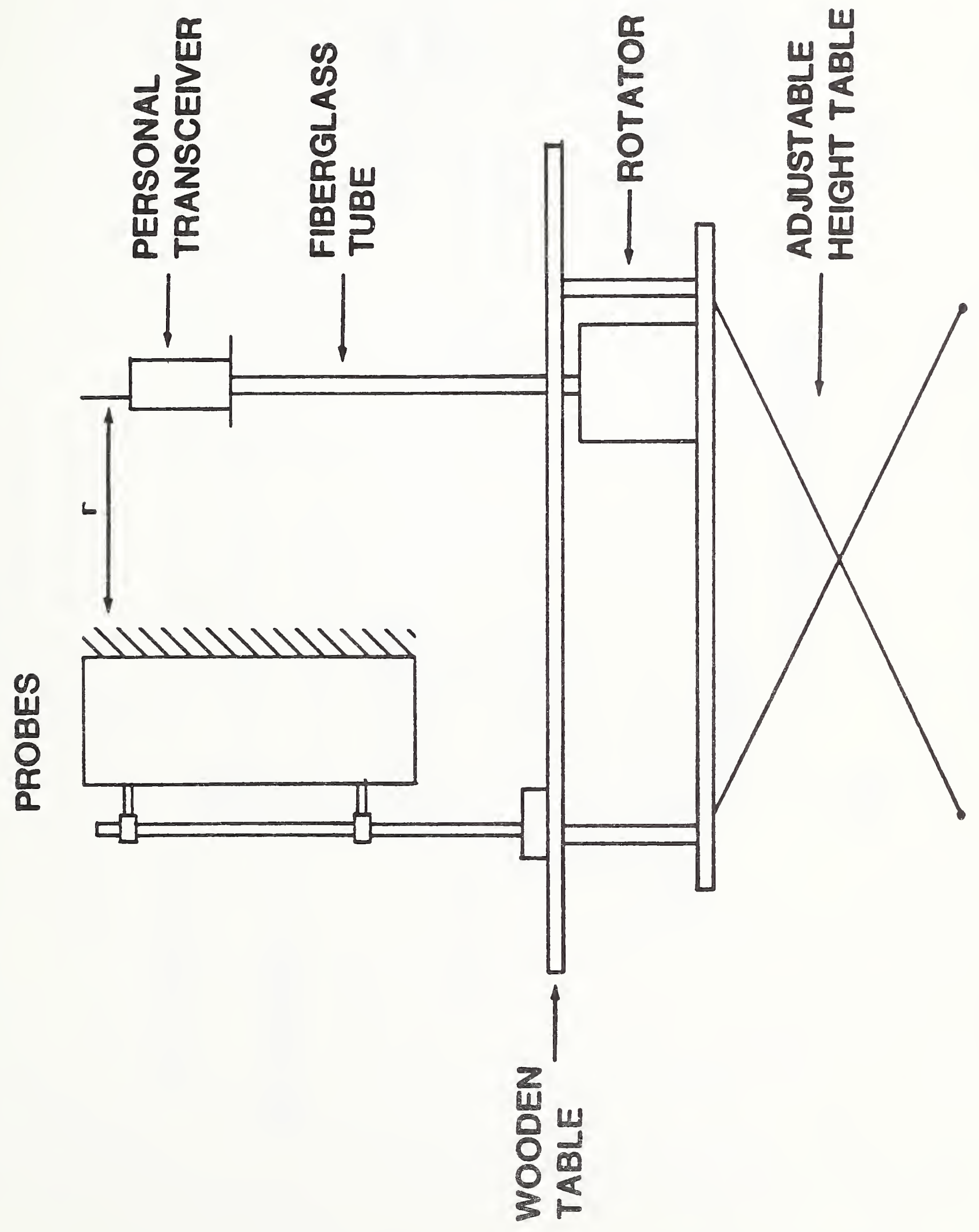

ปั 


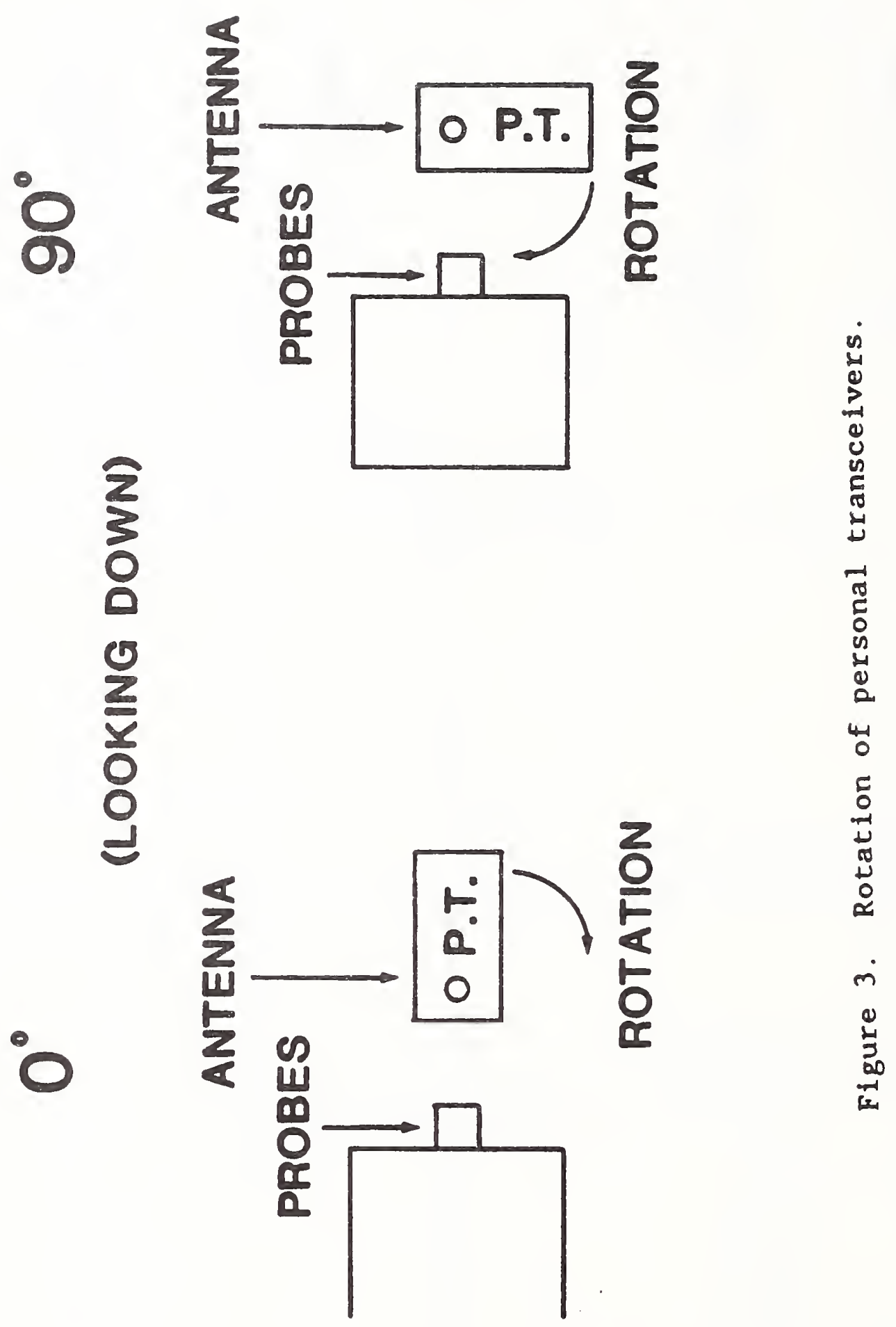




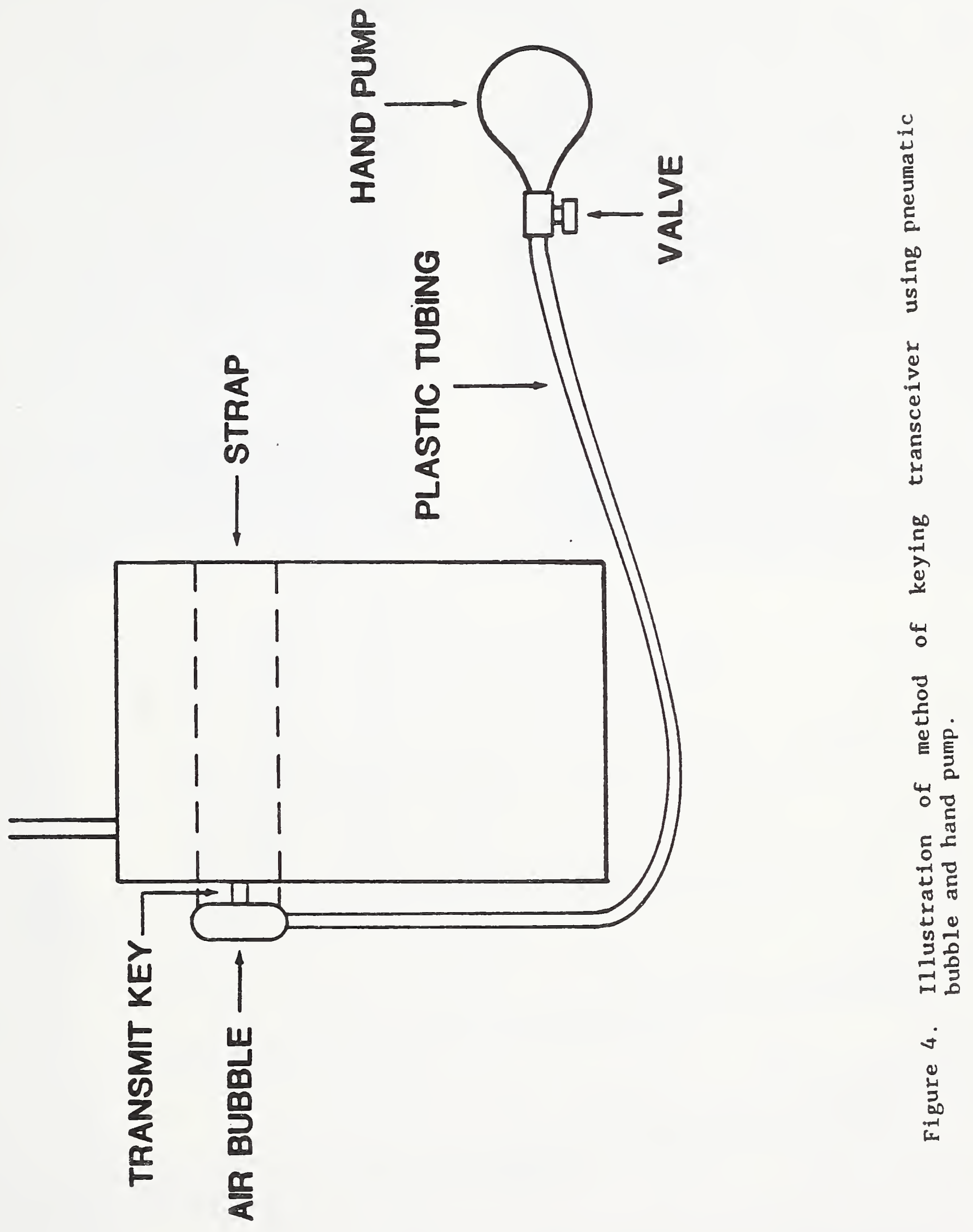




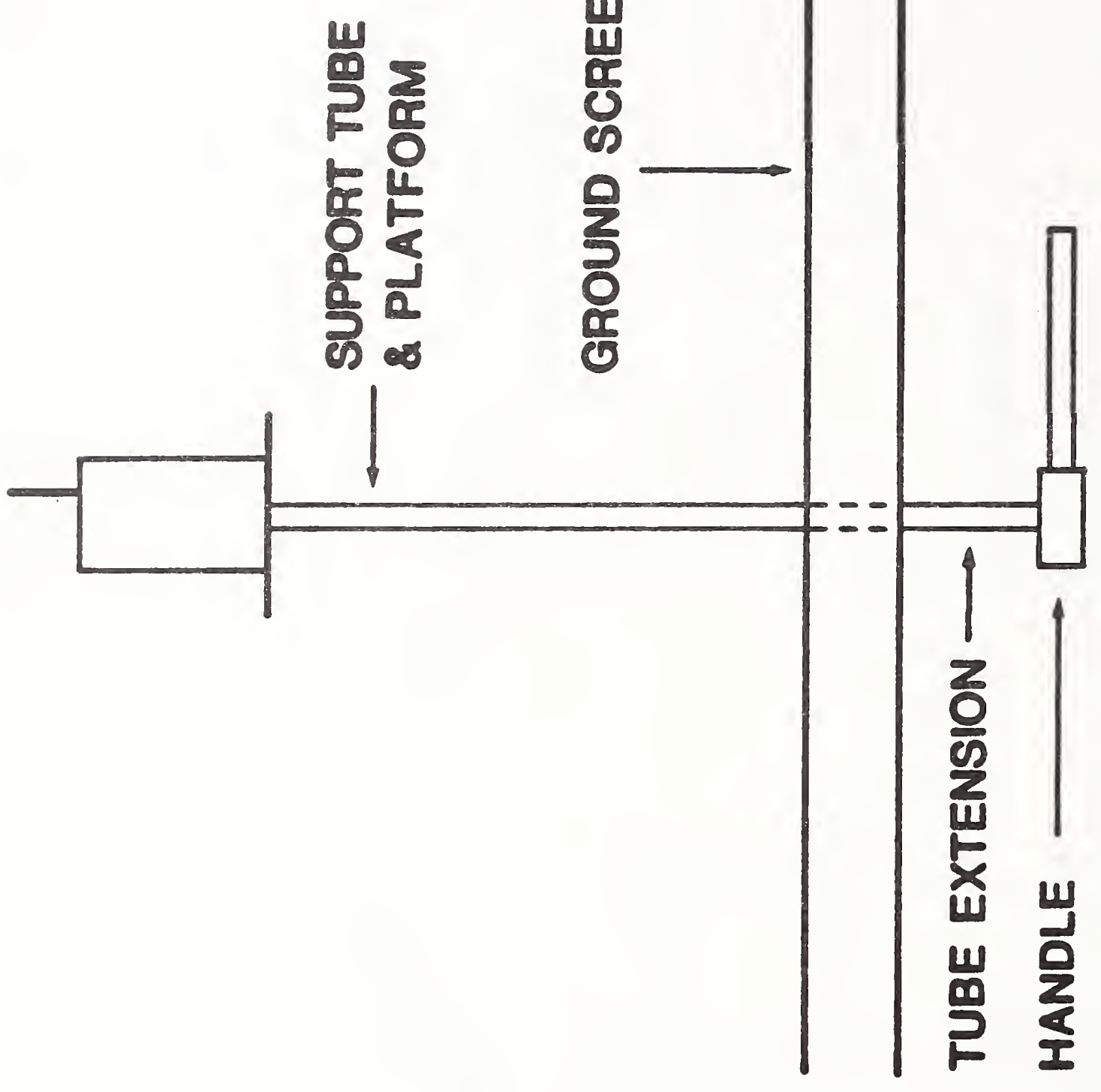

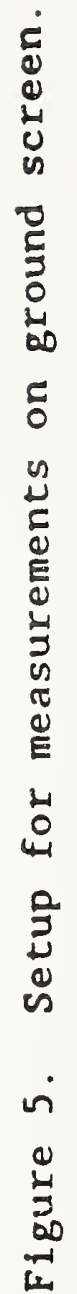




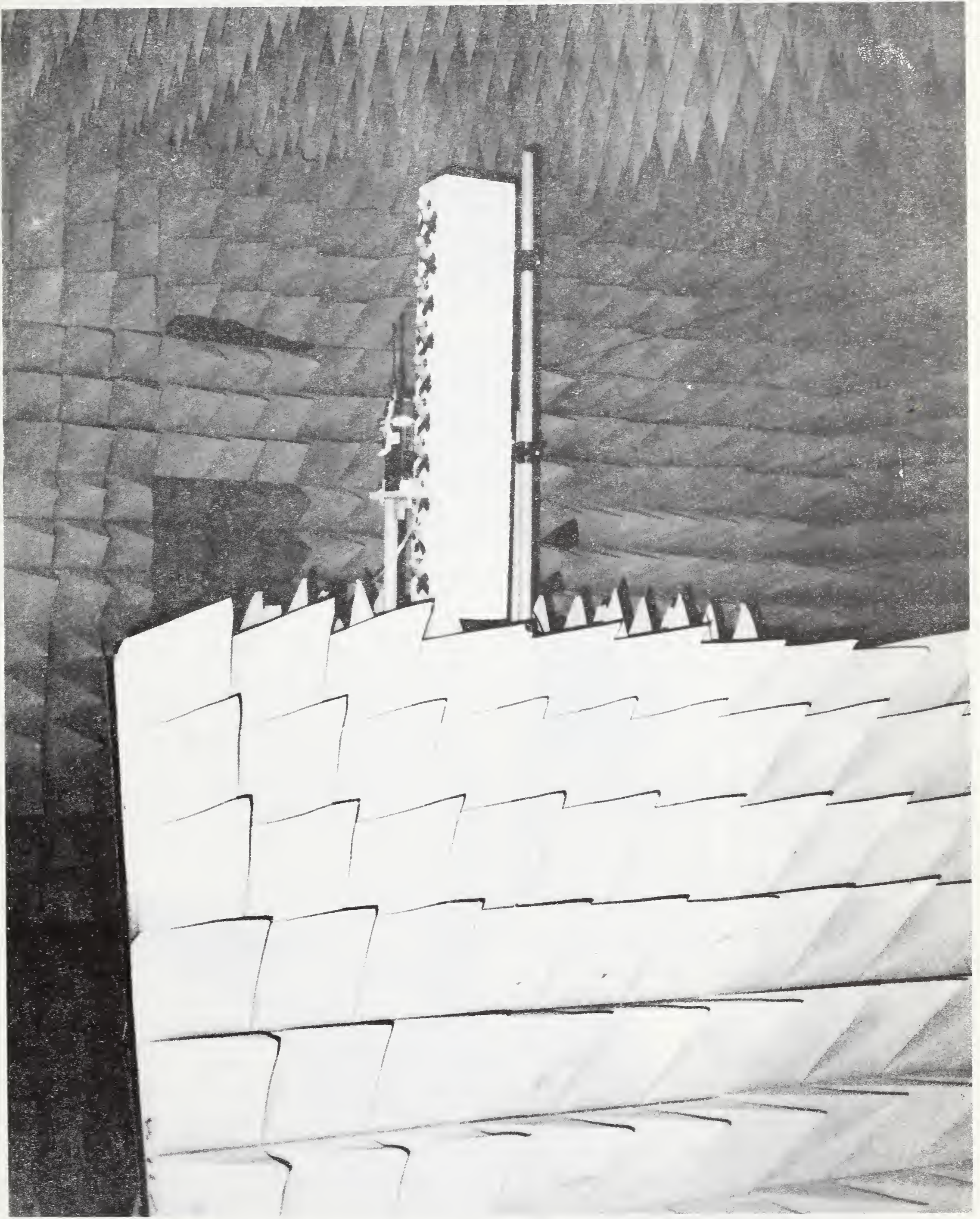

Figure 6. Plcture of setup for measurements inside anechoic chamber. 


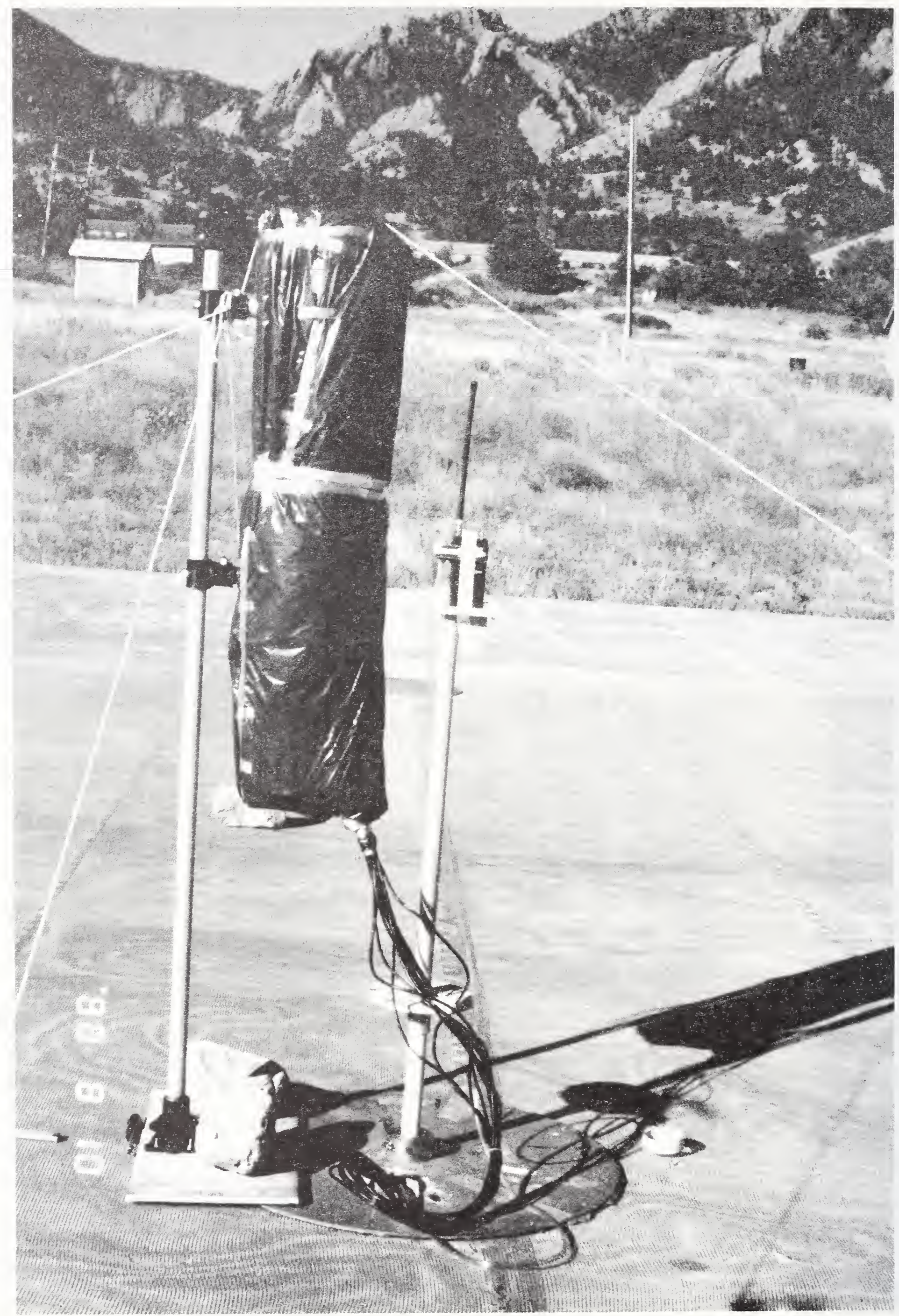

Figure 7. Plcture of setup for measurements on ground screen. Note black plastic cover over probe array to block sunlight. 

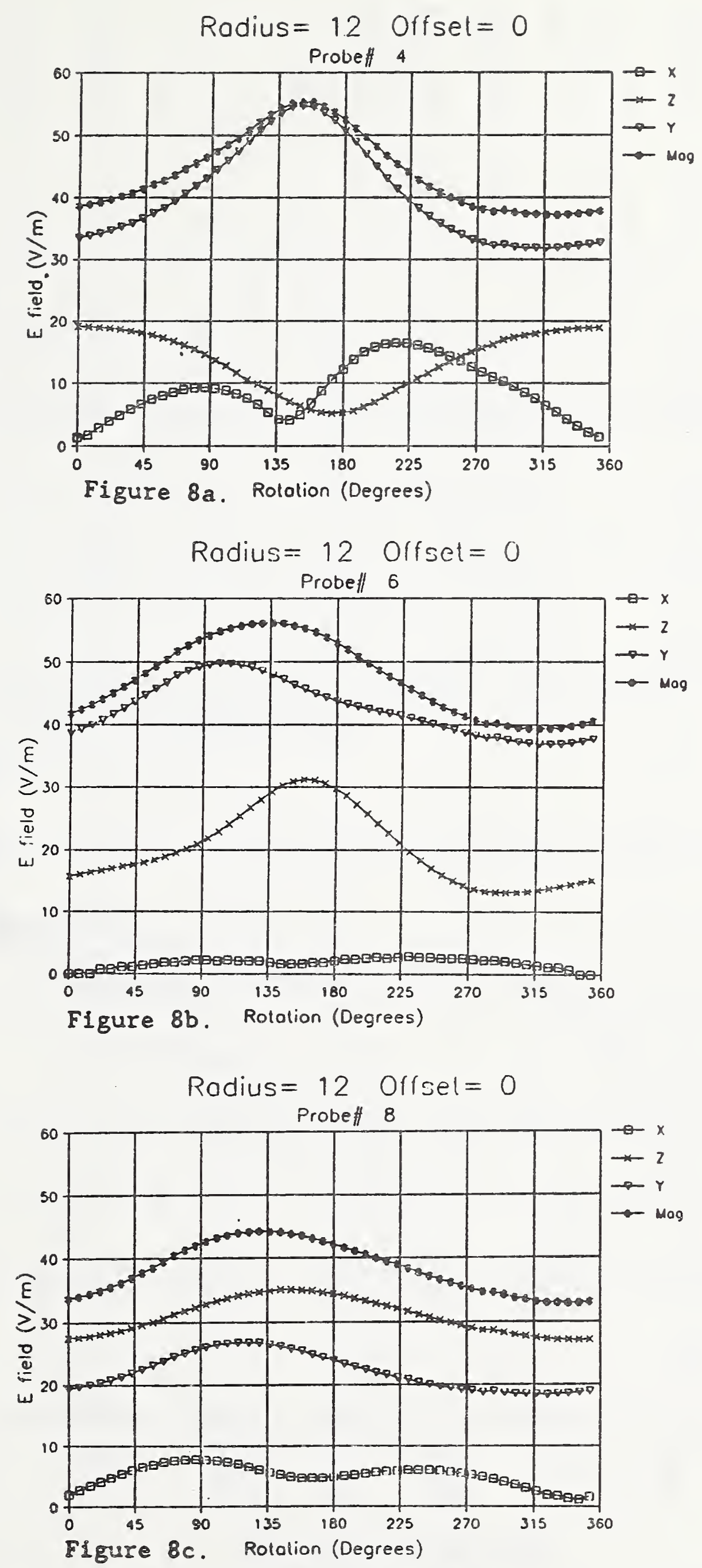

Figure 8. Display of agnitude and $x, y$ and $z$ components of the electric field distribution of probe 4 (figure $8 \mathrm{a}$ ), probe 6 (figure $8 \mathrm{~b}$ ), and probe 8 (figure $8 \mathrm{c}$ ), all at a distance of 12 centimeters from transceiver $\mathrm{R} 823$. 
$-N m+\infty \omega N \infty$

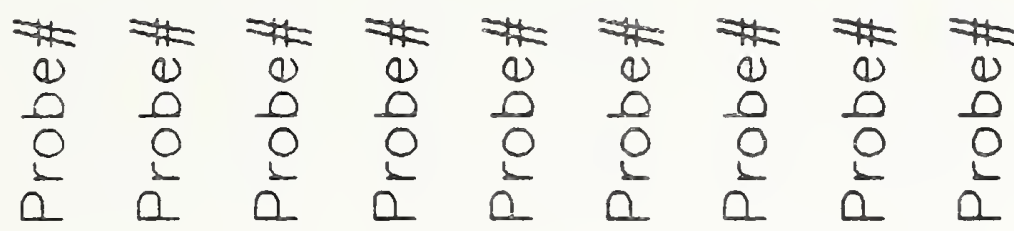

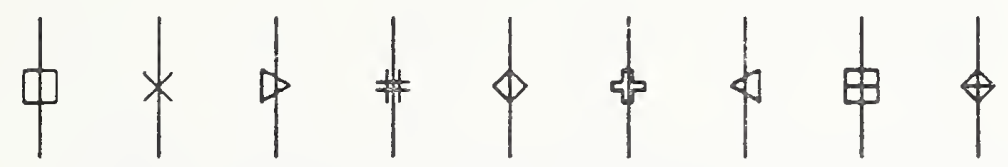

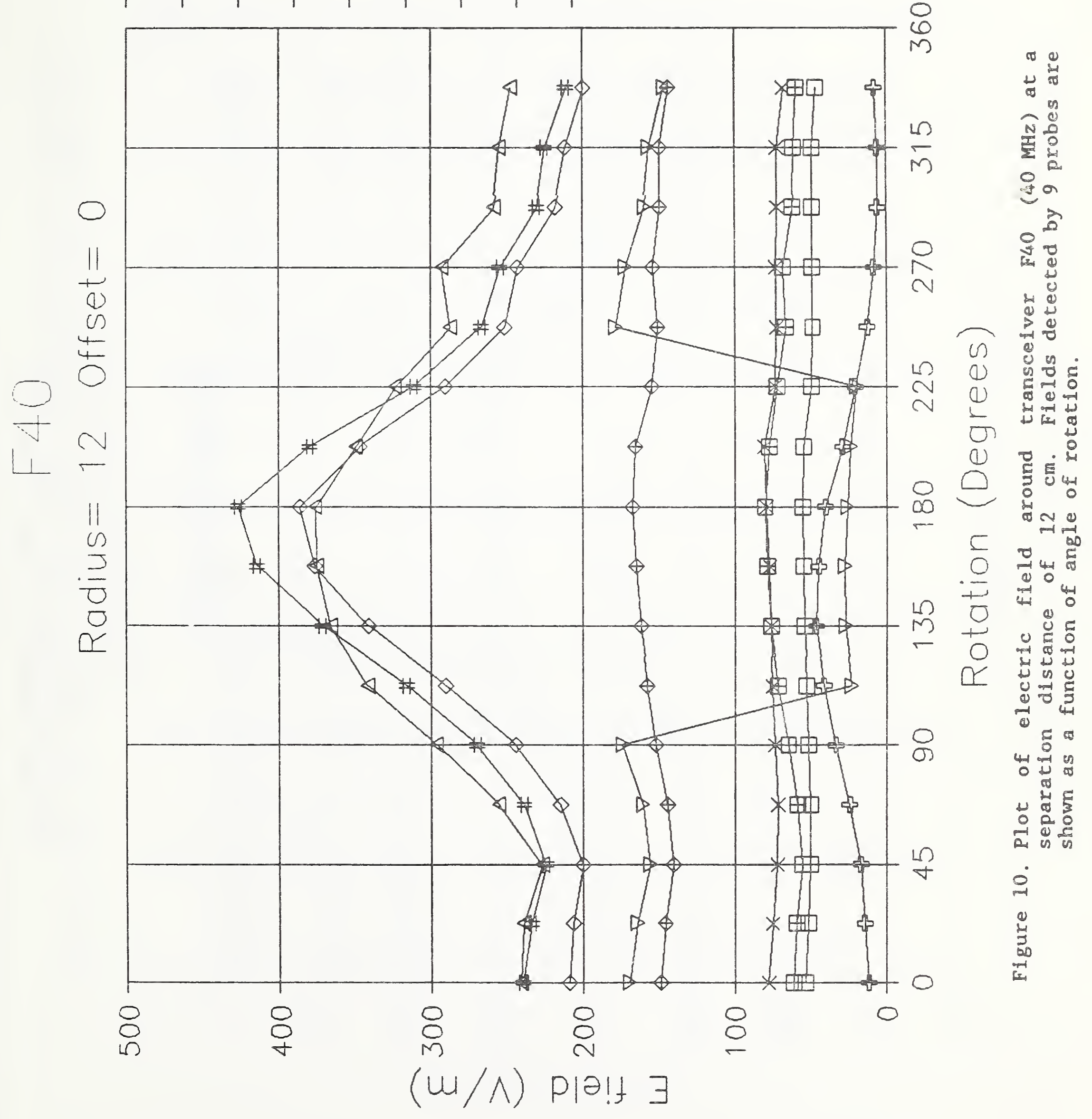


$-N M+\infty \quad \infty N \infty$

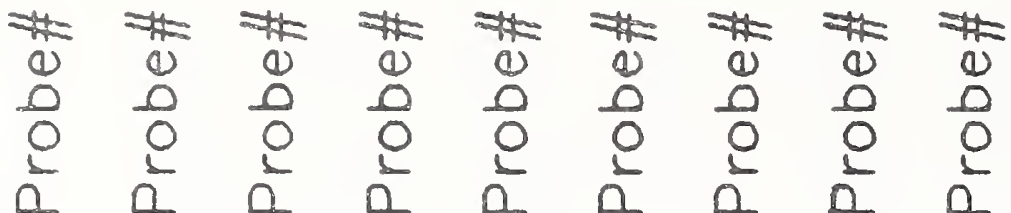
$\phi \star \phi \# \phi \nLeftarrow \phi \phi \phi$

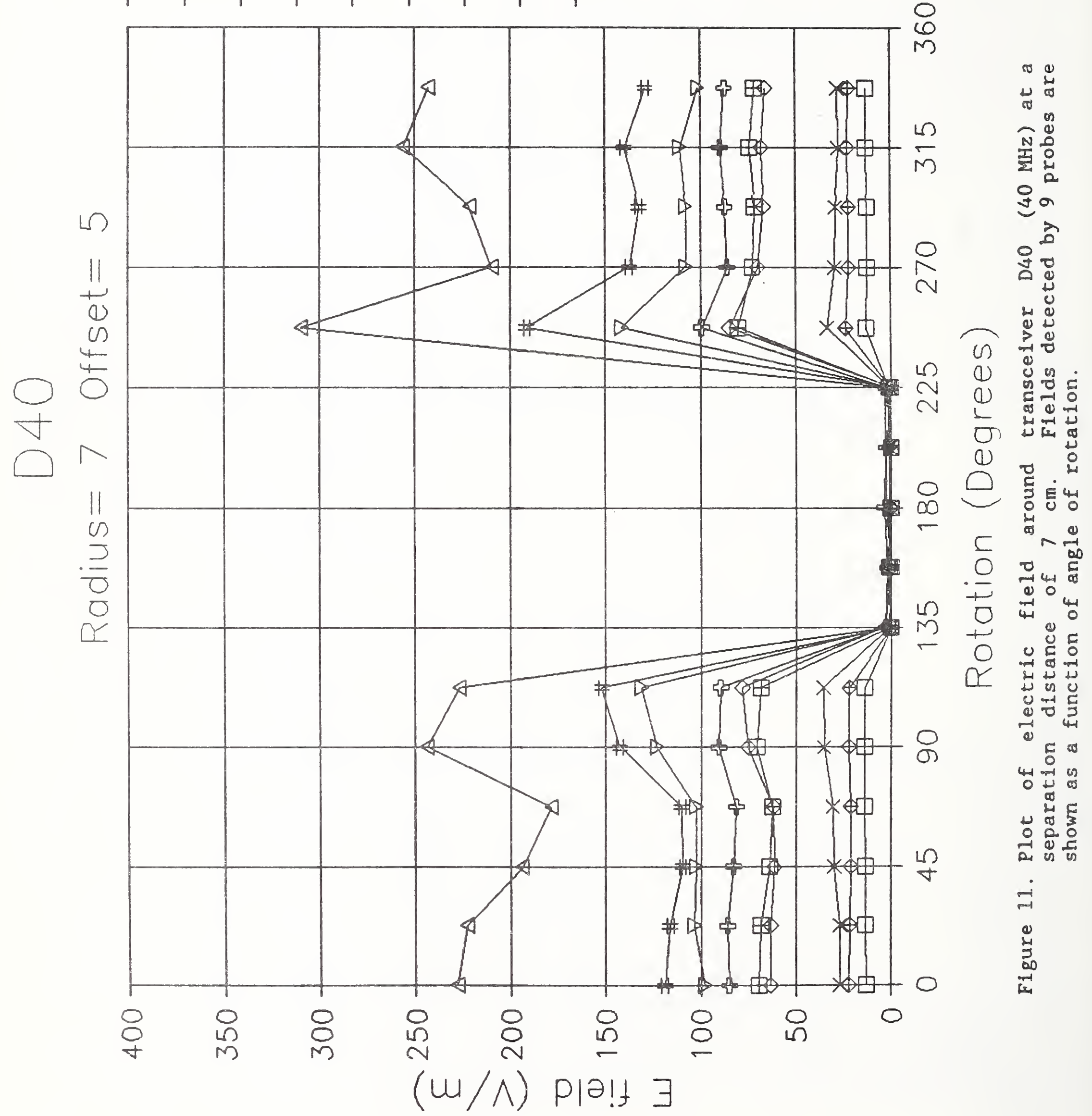


$-N M+\infty \omega N \infty \sigma$

$\begin{array}{ccccccccc}* & * & * & * & * & * & * & * & * \\ 0 & 0 & 0 & 0 & 0 & 0 & 0 & 0 & 0 \\ 0 & 0 & 0 & 0 & 0 & 0 & 0 & 0 & 0 \\ 0 & 0 & 0 & 0 & 0 & 0 & 0 & 0 & 0 \\ 0 & 0 & 0 & 0 & 0 & 0 & 0 & 0 & 0\end{array}$ 中*中\#

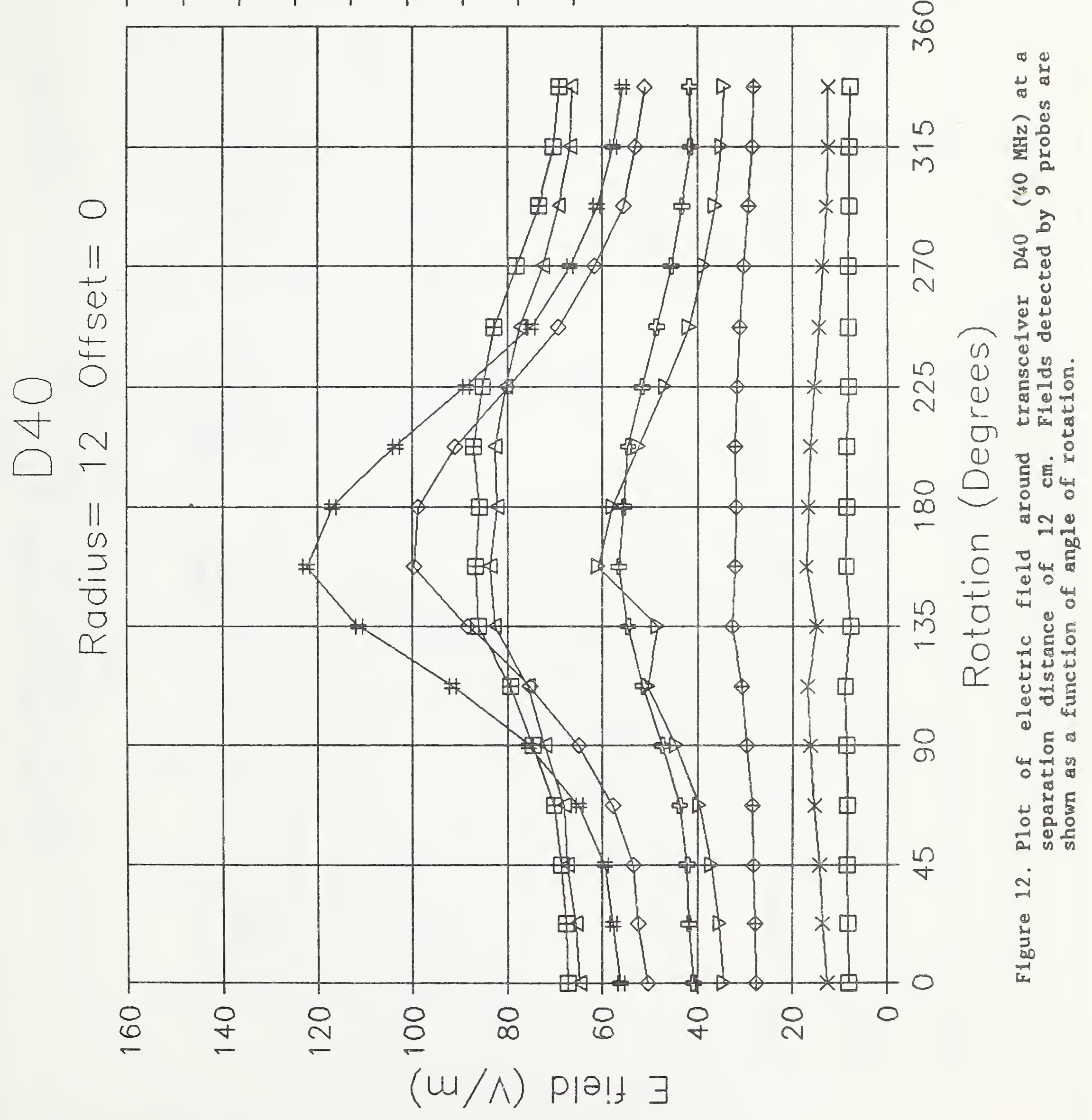


$-N M+\infty \omega N \infty$

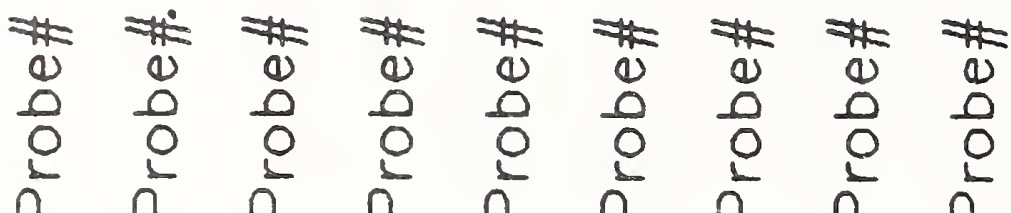
$\phi * \phi \neq \phi \phi \phi \phi \phi$

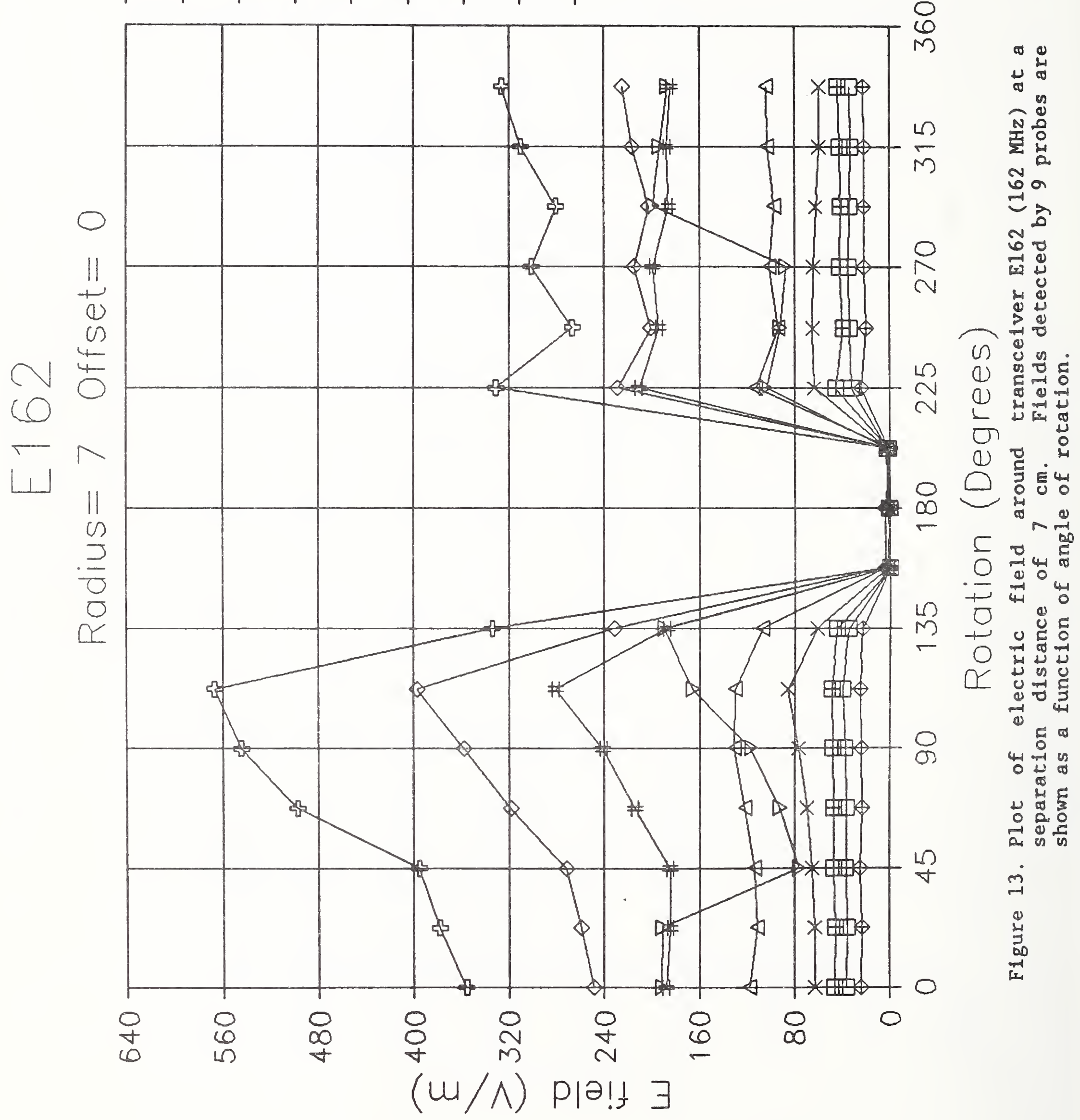


$-N M+\infty \quad 0 \quad \infty \quad 0$

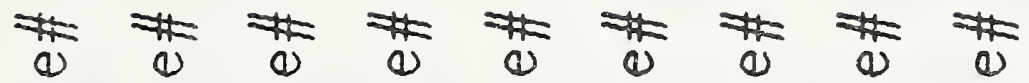

$\begin{array}{llllllll}0 & 0 & 0 & 0 & 0 & 0 & 0 & 0 \\ 0 & 1 & 0 & 0 & 0 & 0 & 0 & 0\end{array}$

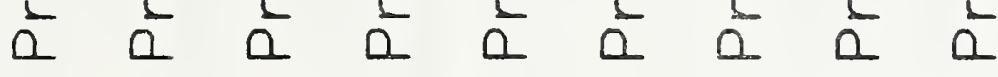

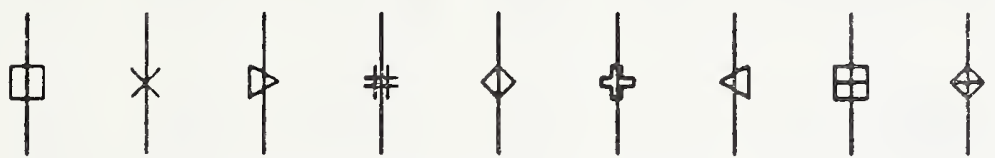

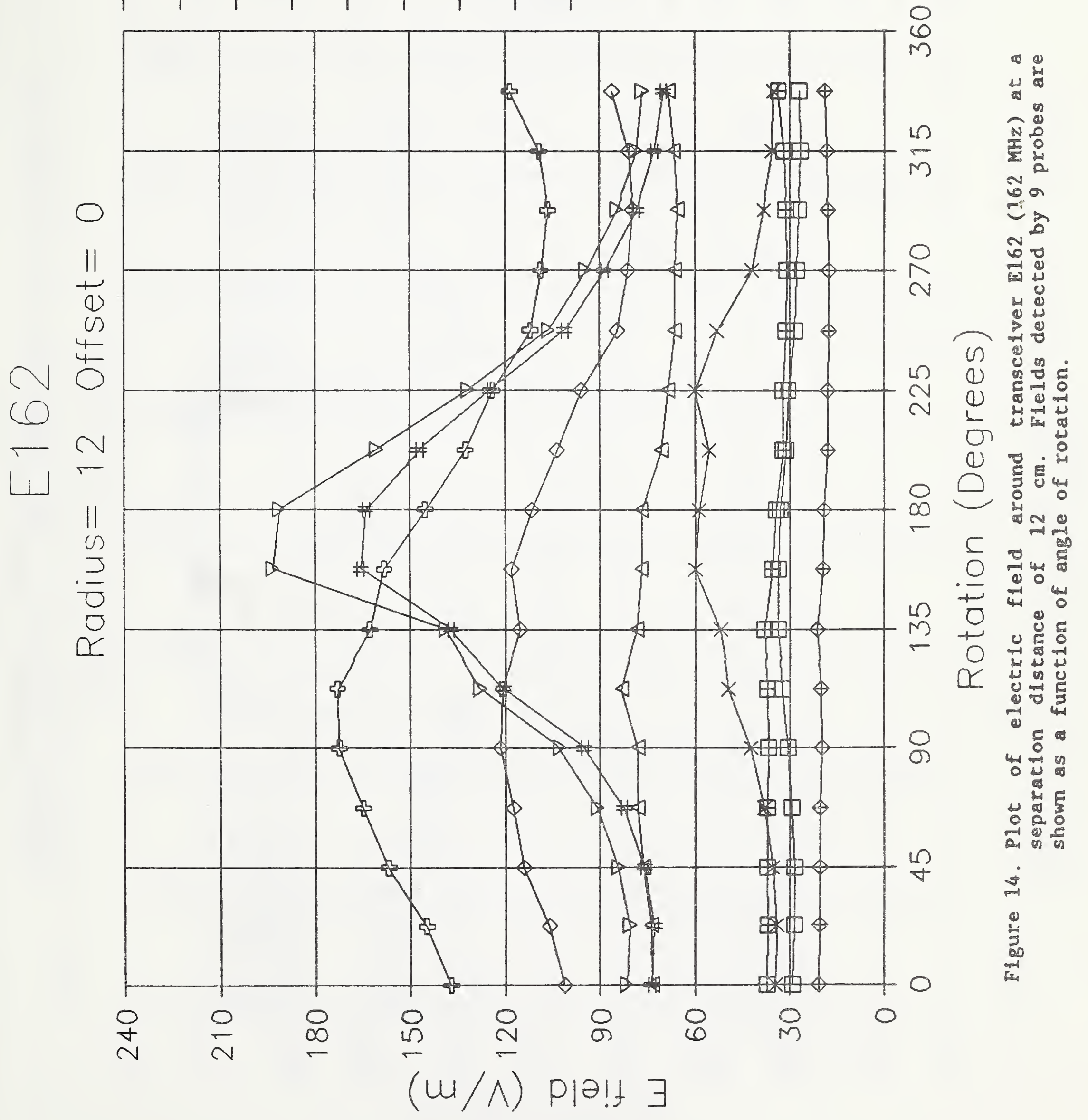


- $N M+\infty 6 \wedge \infty a$

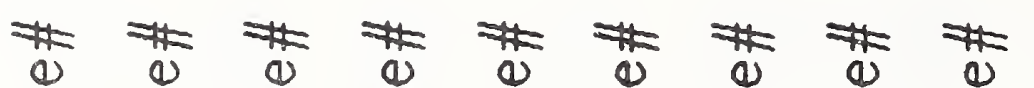

$\begin{array}{lllllllll}0 & 0 & 0 & 1 & 0 & 0 & 0 & 0 & 0 \\ 0 & 0 & 0 & 0 & 0 & 0 & 0 & 0 & 0 \\ 0 & 0 & 0 & 0 & 0 & 0 & 0 & 0 & 0\end{array}$

¿ व व

$\phi \star \phi \neq \phi \phi \phi \phi \phi$

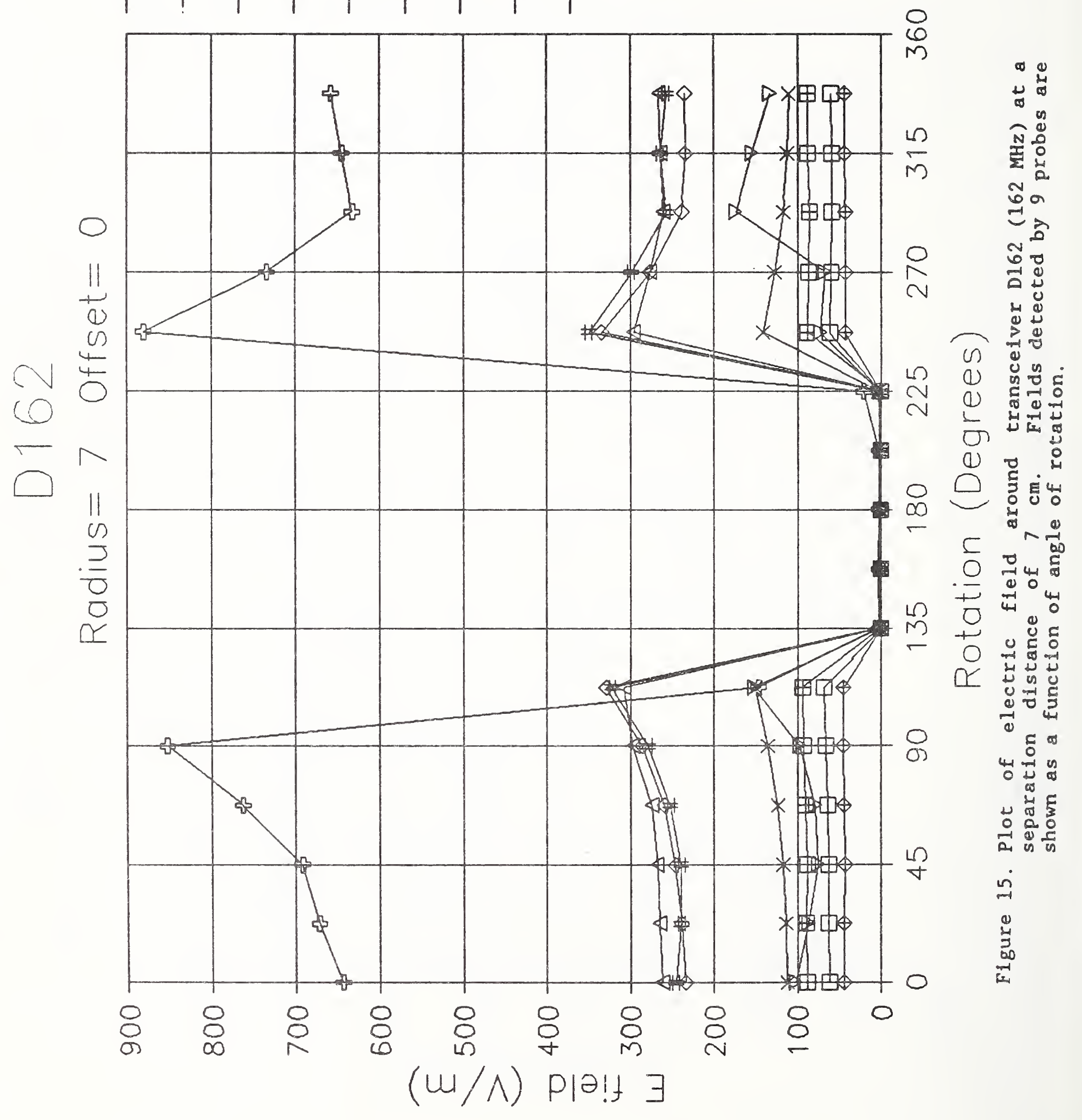


$-N M+\infty \omega N \infty$

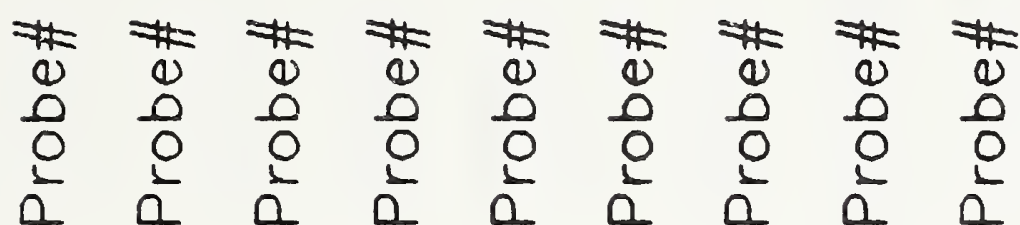
$\phi * \phi \neq \phi \notin \phi \phi \phi$

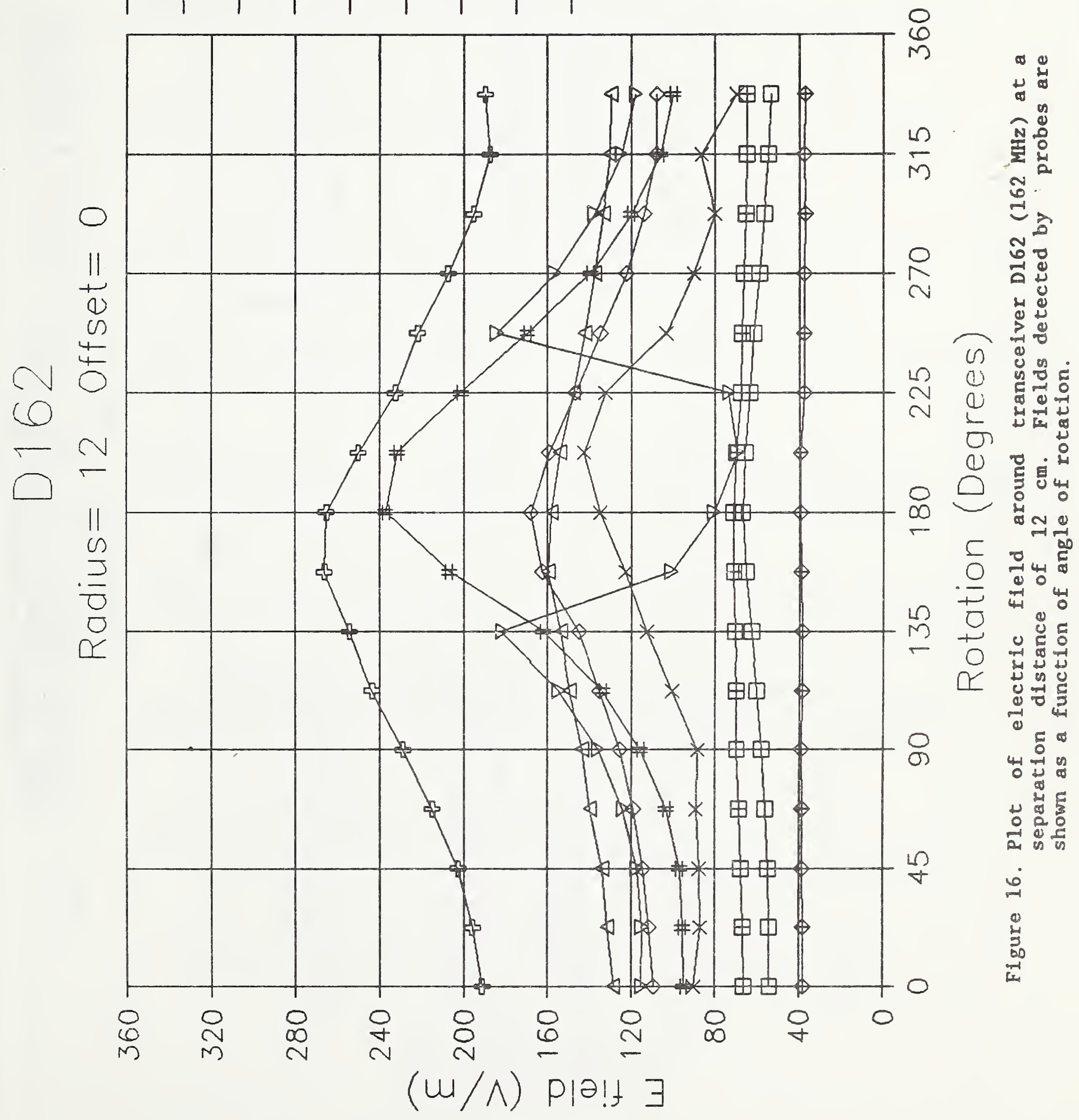


$-N M+\infty \omega N \infty$

$\begin{array}{lllllllll}* & * & * & * & * & * & * & * & * \\ 0 & 0 & 0 & 0 & 0 & 0 & 0 & 0 & 0 \\ 0 & 0 & 0 & 0 & 0 & 0 & 0 & 0 & 0 \\ 0 & 0 & 0 & 0 & 0 & 0 & 0 & 0 & 0 \\ 1 & 1 & 0 & 0 & 0 & 0 & 0 & 0 & 0\end{array}$

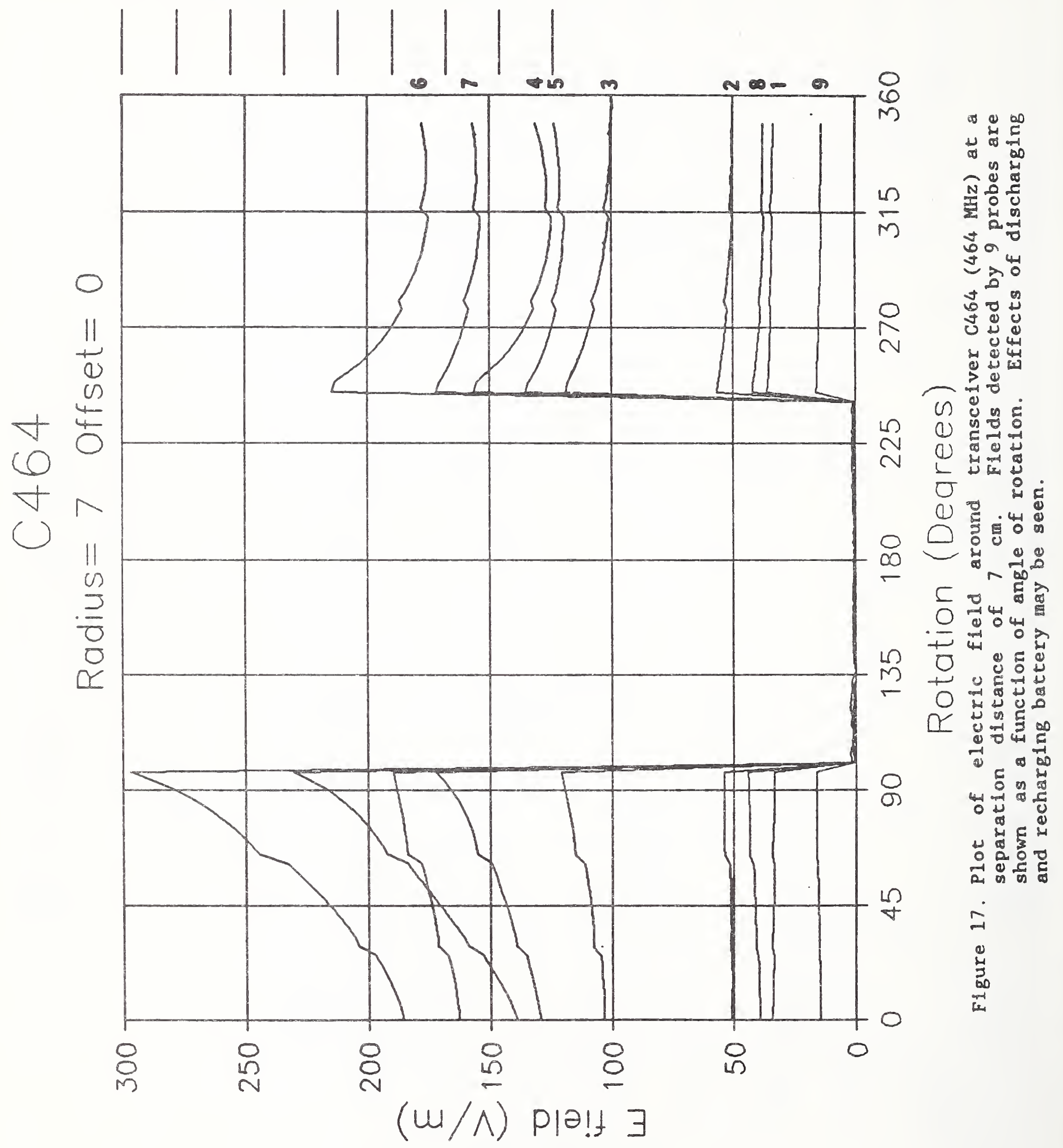


$-N M+\infty \quad+\infty N$

$\begin{array}{ccccccccc}* & * & * & * & * & * & * & * & * \\ 0 & 0 & 0 & 0 & 0 & 0 & 0 & 0 & 0 \\ 0 & 0 & 0 & 0 & 0 & 0 & 0 & 0 & 0 \\ 0 & 0 & 0 & 0 & 0 & 0 & 0 & 0 & 0 \\ 0 & 1 & 0 & 0 & 0 & 0 & 0 & 0 & 0\end{array}$

$1|1| 1|1|$

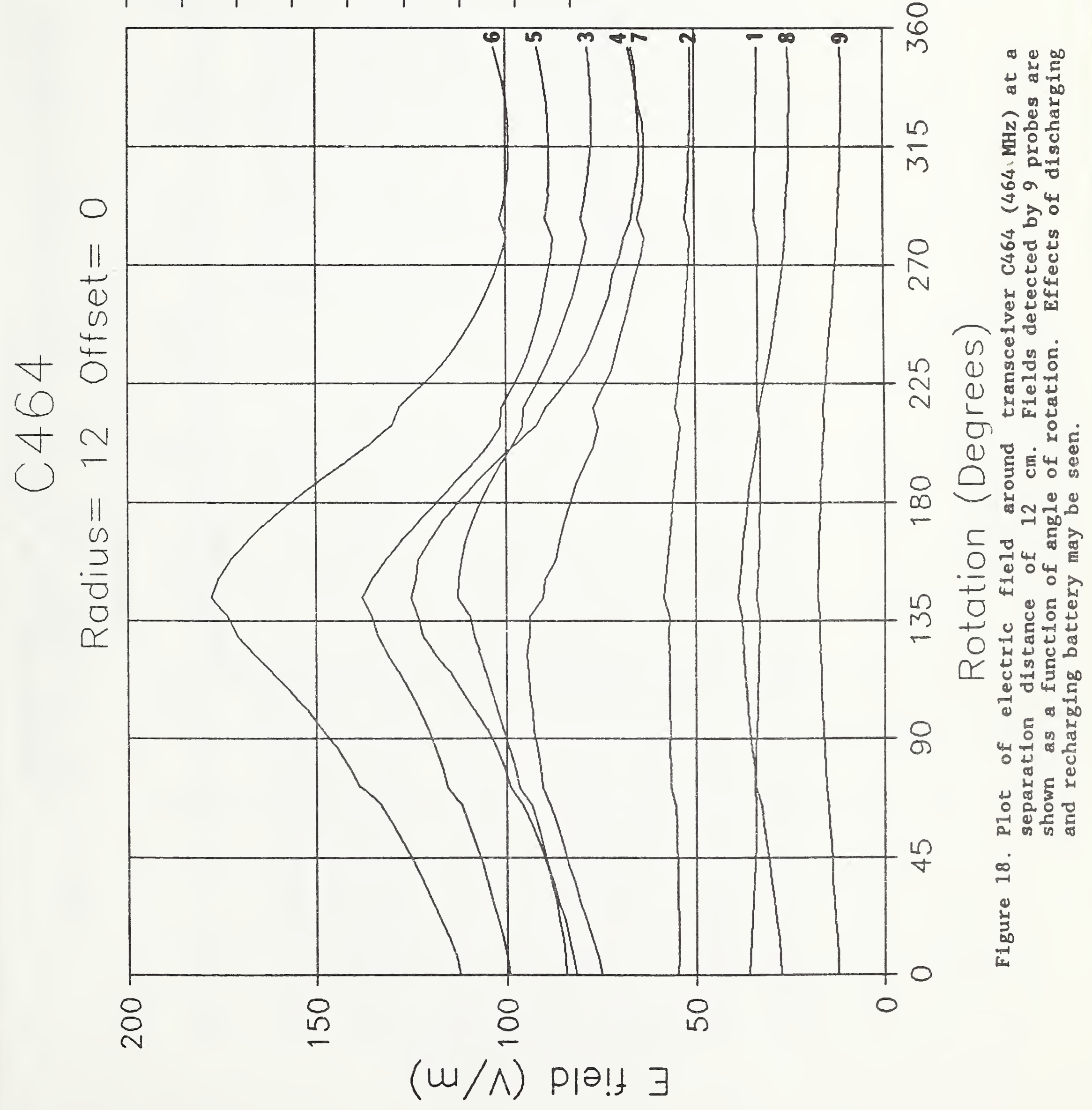


$-N M+\infty N \infty$

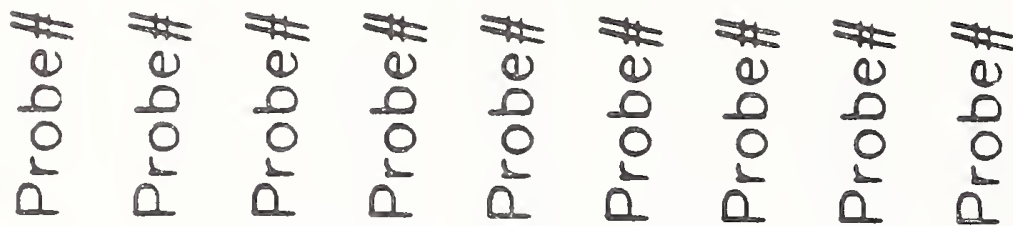

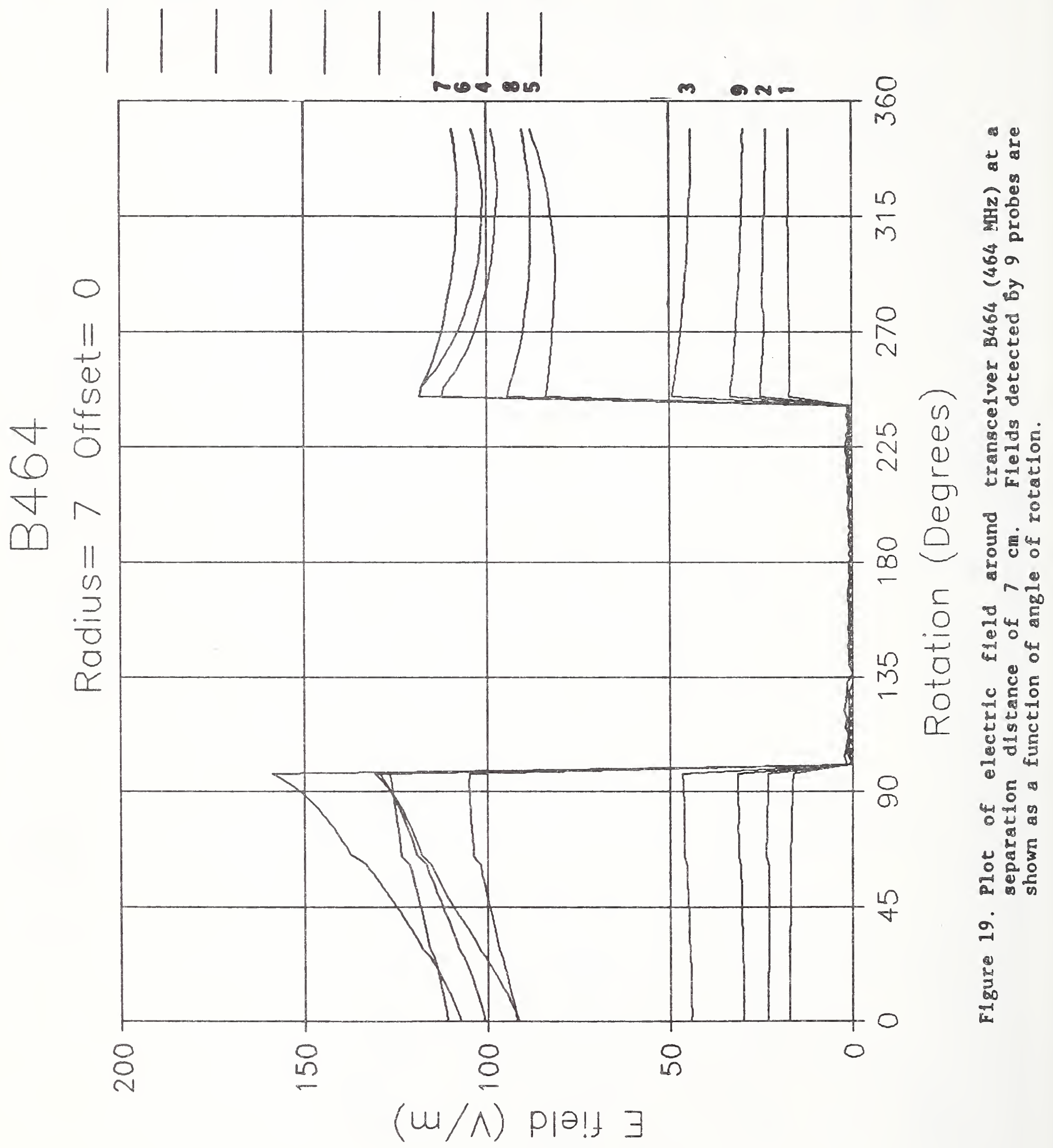


- $N M+\infty \pi N \infty$

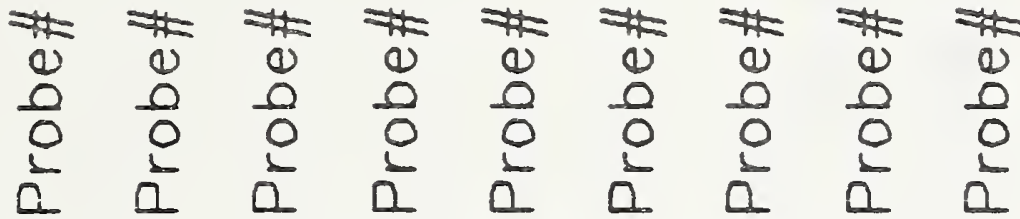

$1|1| 1|1|$

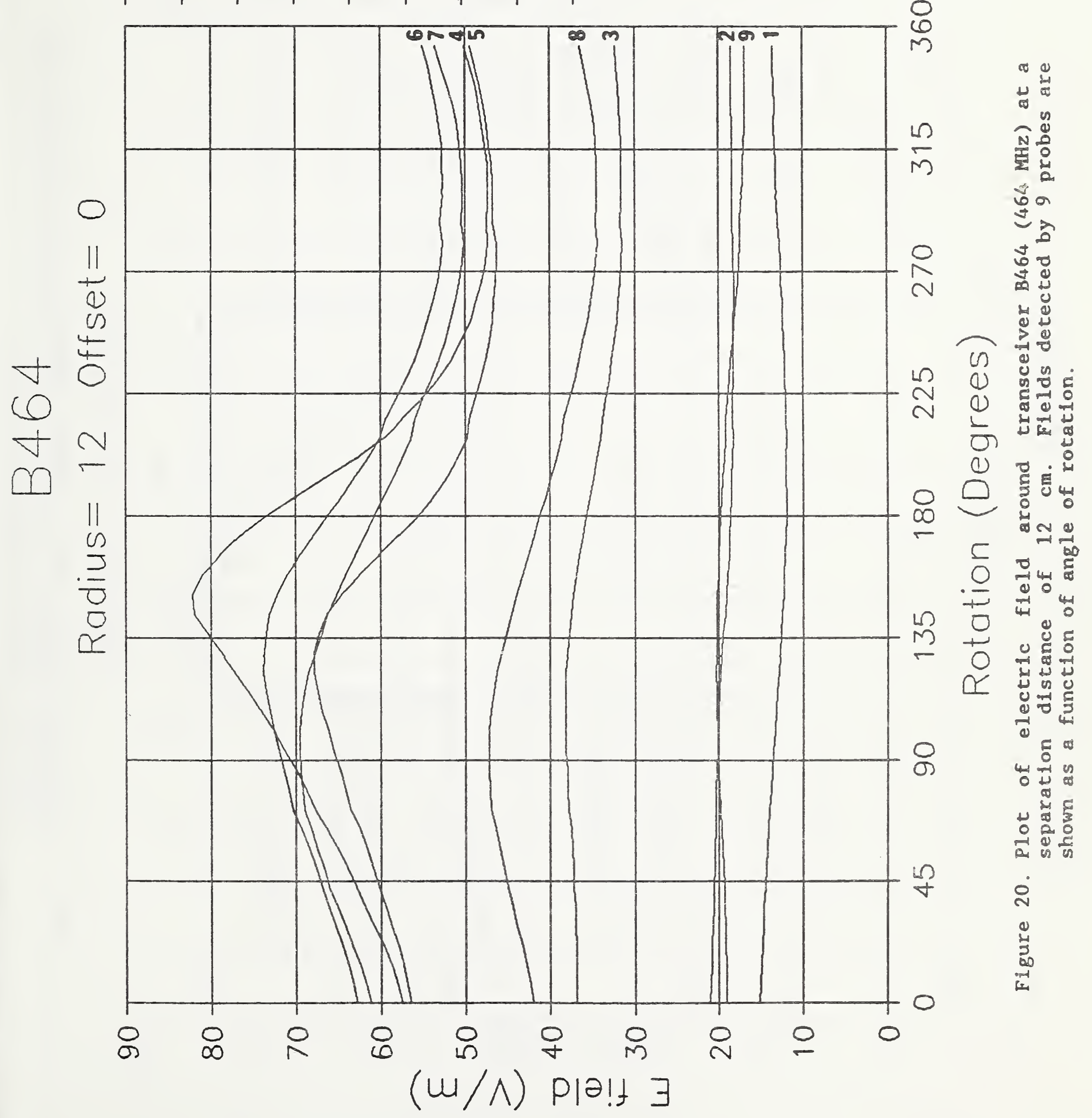


$-N M+\infty 100000$

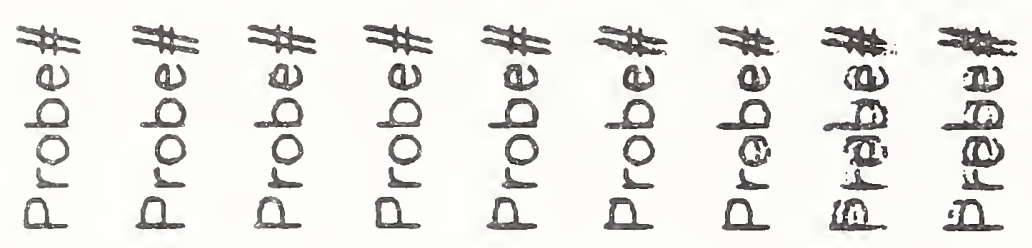

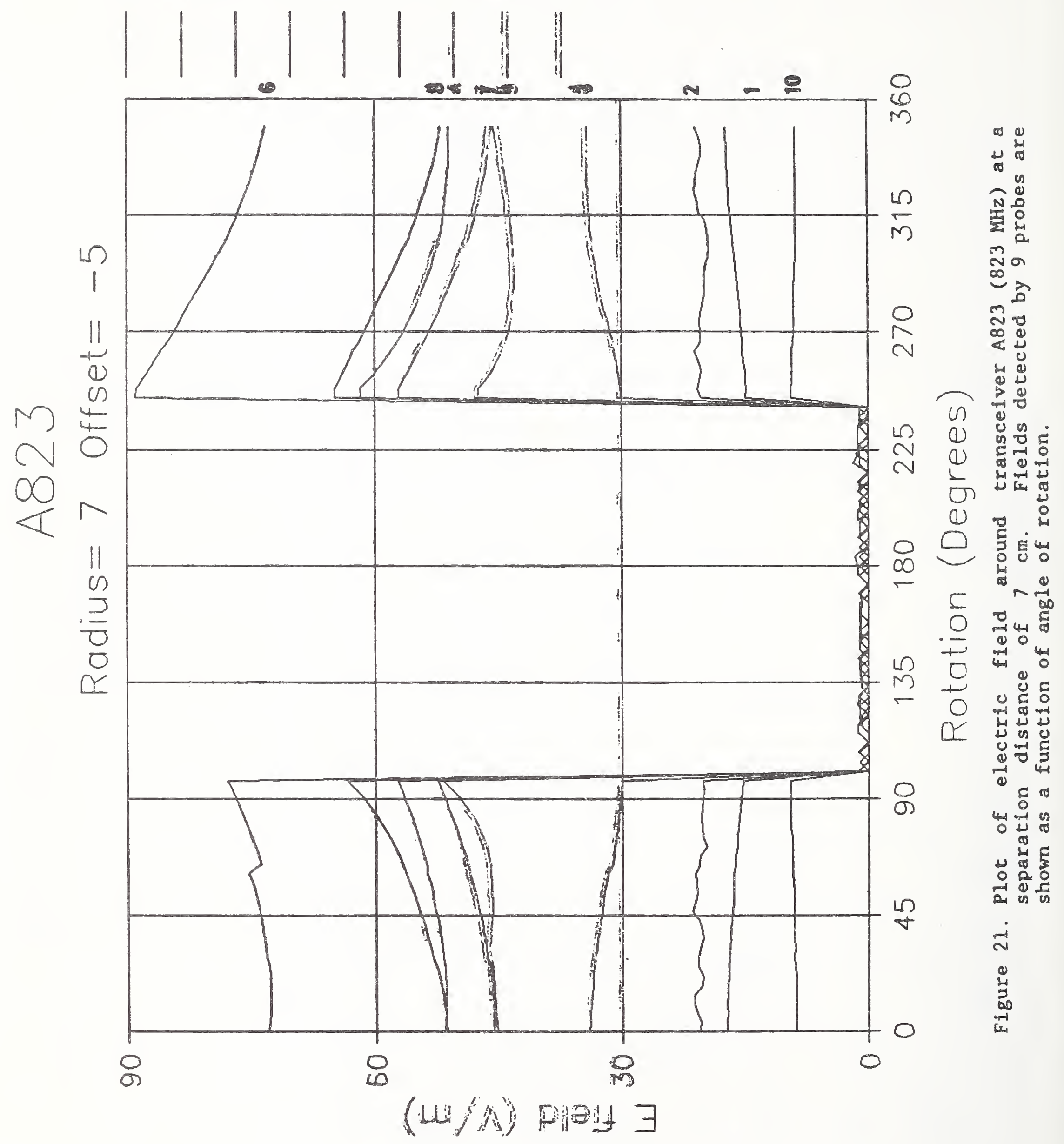


- NM + D $6 N^{\circ}$

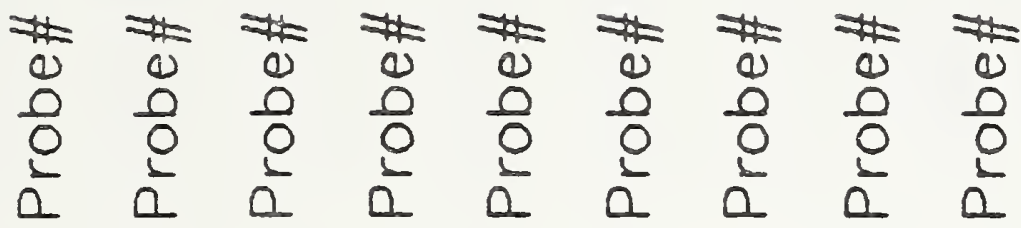

$|1||||| \mid$

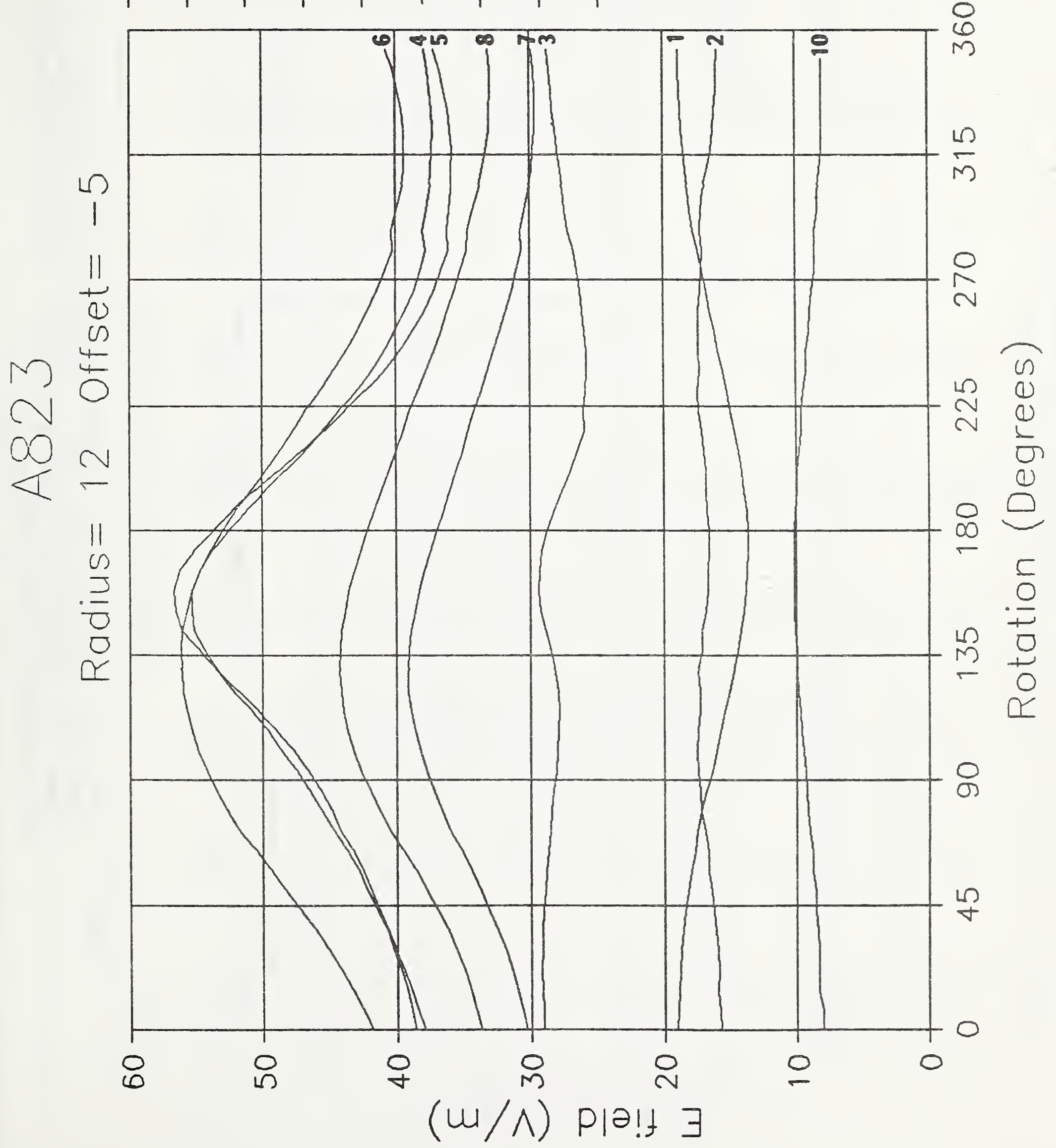

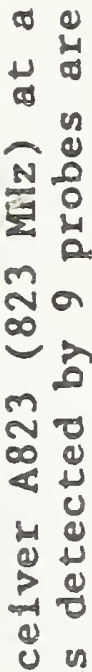

(1) वे

(1) ध क्ष

L $\sum_{0 \rightarrow 0}^{-1}$

(1)

돌

ร०ण

๘ $\simeq$

$5 \quad 0$

$\prod_{-1}^{\infty} 0$

(2)

บ

I $य$

记

(1) 5

بั口ำ

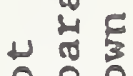

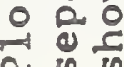

ก

$\overbrace{\substack{0 \\ 0}}^{0}$ 


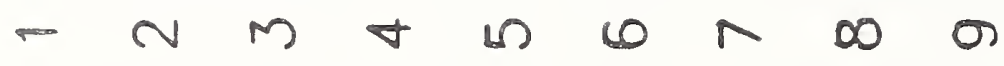

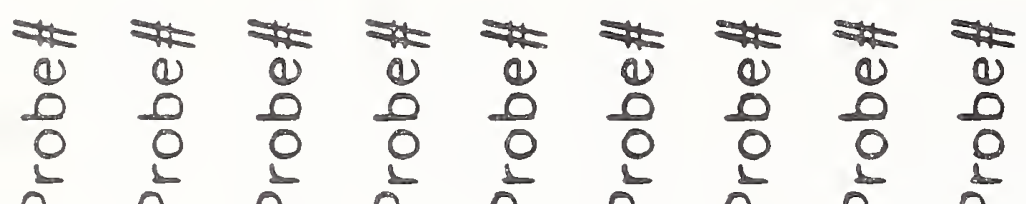

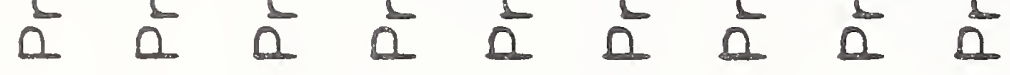

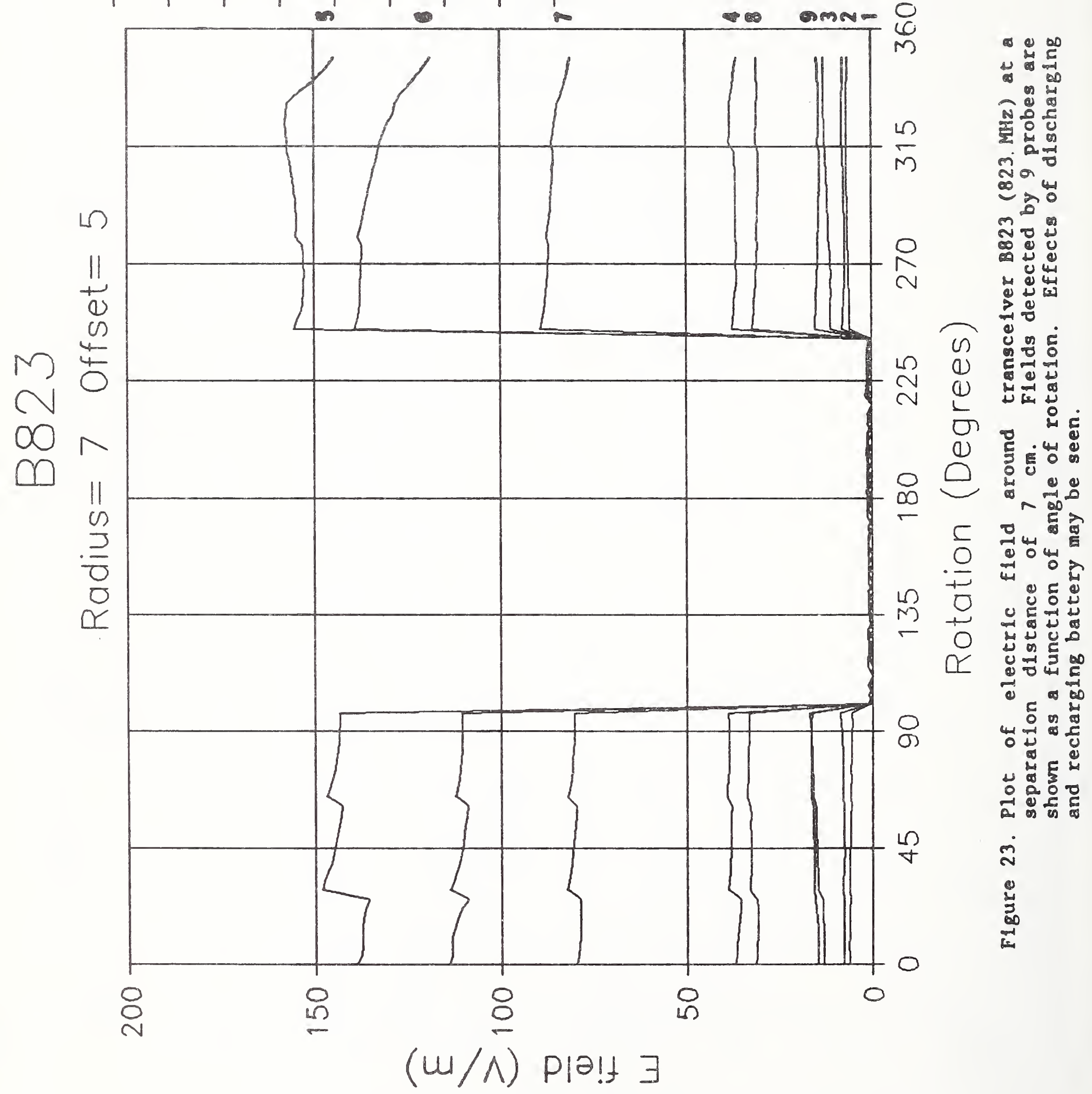


- $N M+\infty N \infty$

$\begin{array}{lllllllll}* & H & * & * & * & * & * & * & * \\ 0 & 0 & 0 & 0 & 0 & 0 & 0 & 0 & 0 \\ 0 & 0 & 0 & 0 & 0 & 0 & 0 & 0 & 0 \\ 0 & 0 & 0 & 0 & 0 & 0 & 0 & 0 & 0 \\ 0 & 0 & 0 & 0 & 0 & 0 & 0 & 0 & 0\end{array}$
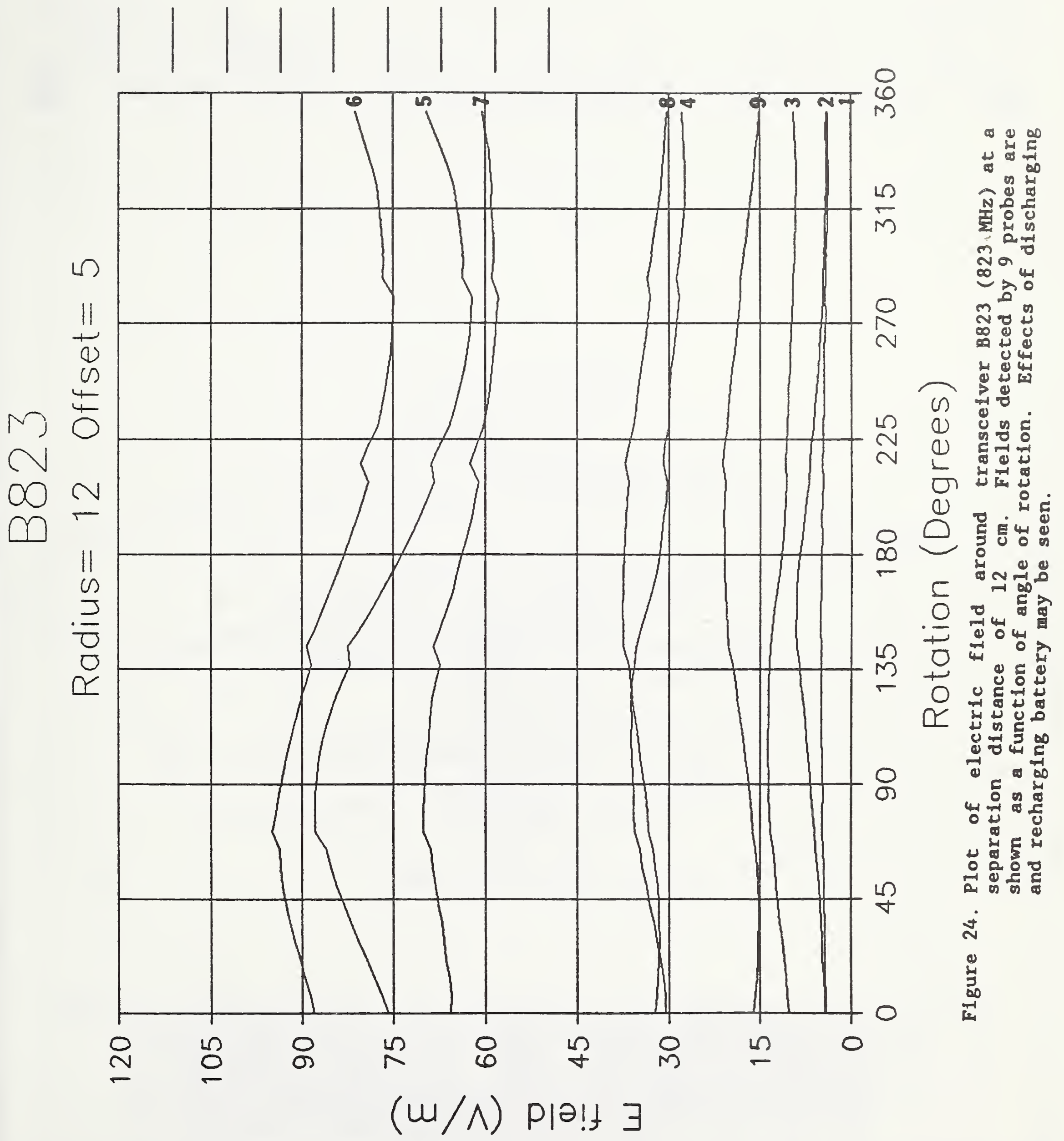
F40

RRDIUS $=7$

NUMBER OF POINTS $=16$

$=$ MAXIMUM POINT: $720.30-112.50$

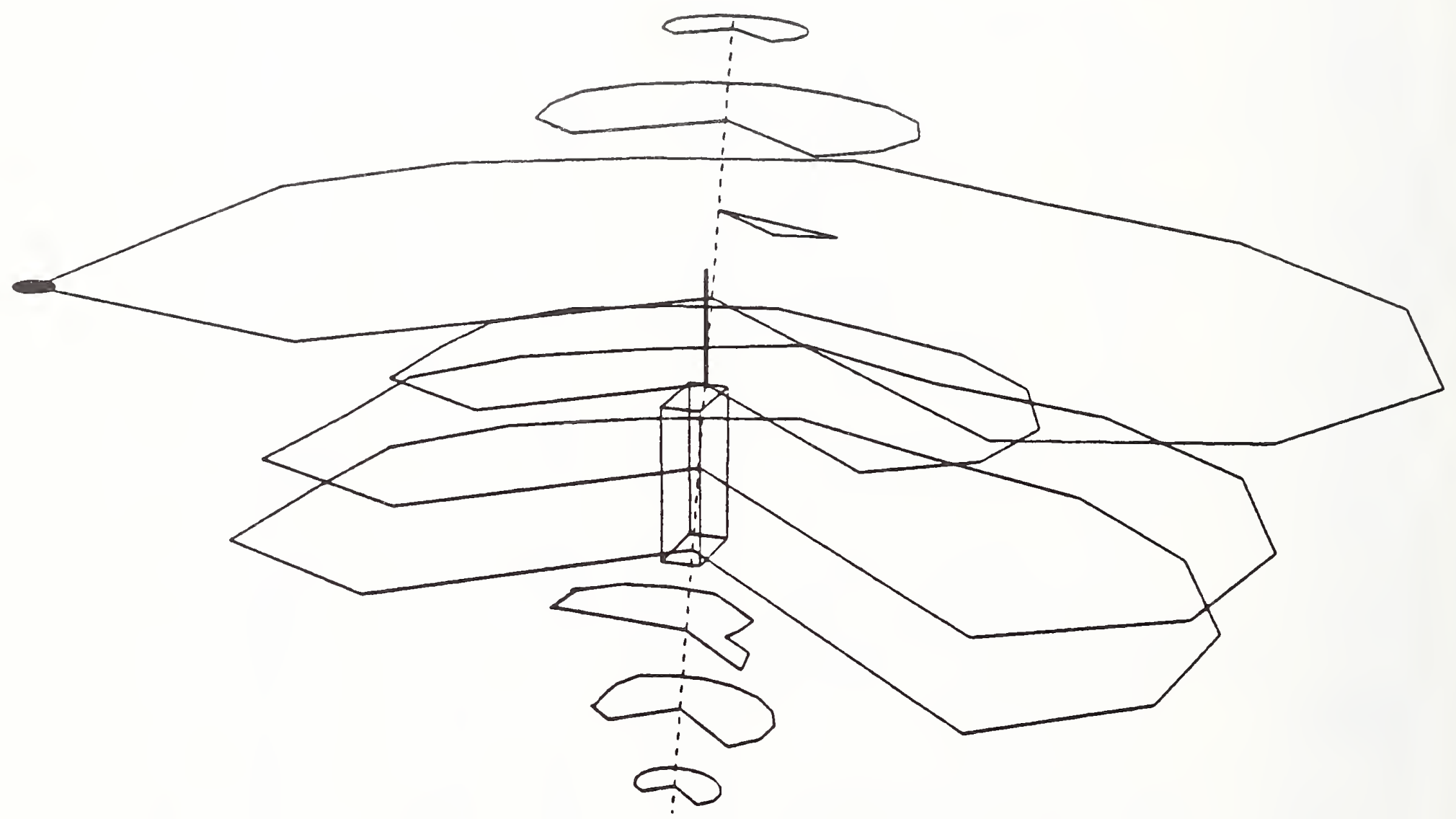

Figure 25. Three-dimensional plot of magnitude of electric field around transceiver $F 40 \quad(40 \mathrm{MHz})$. Radii of disks are proportional to magnitude of electric field. Separation distance between transceiver antenna and probes is in centimeters (RADIUS $=7$ ). Maximum value of field strength is marked with black dot. The two numbers after MAXIMUM POINT are electric field strength in volts per meter and angle of rotation in degrees. 
F40

RADIUS $=12$

NUMBER OF POINTS $=16$

- MRXIMUM POINT: $426.43 \quad 180.00$

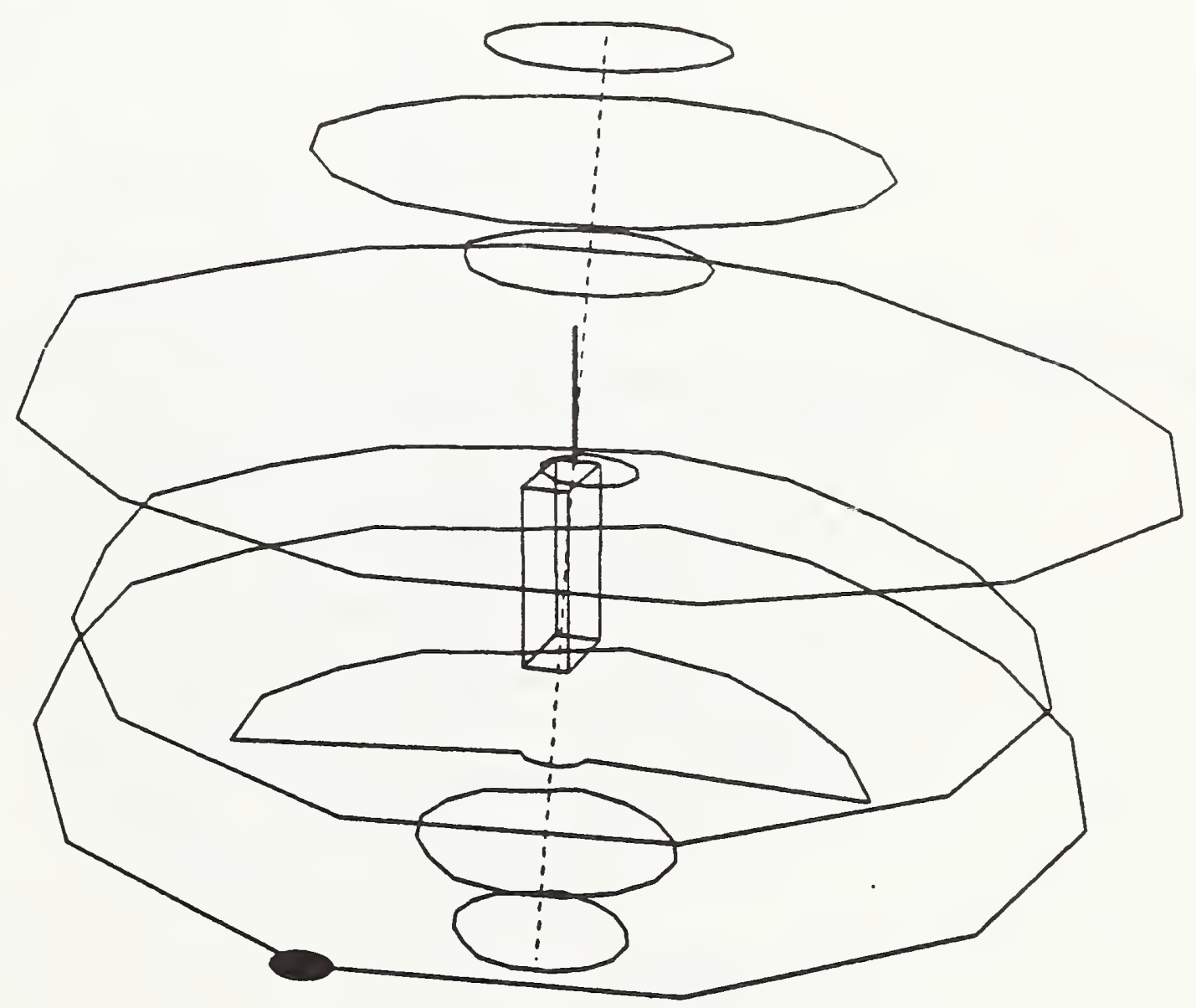

Figure 26. Three-dimensional plot of magnitude of electric field around transceiver F40 (40 MHz). Radii of disks are proportional to magnitude of electric field. Separation distance between transceiver antenna and probes is in centimeters (RADIUS $=12$ ). Maximum value of field strength is marked with black dot. The two numbers after MAXIMUM POINT are electric field strength in volts per meter and angle of rotation in degrees. 
D40

RADIUS $=7$

NUMBER OF POINTS $=16$

= MAXIMUM POINT: $309.60-112.50$

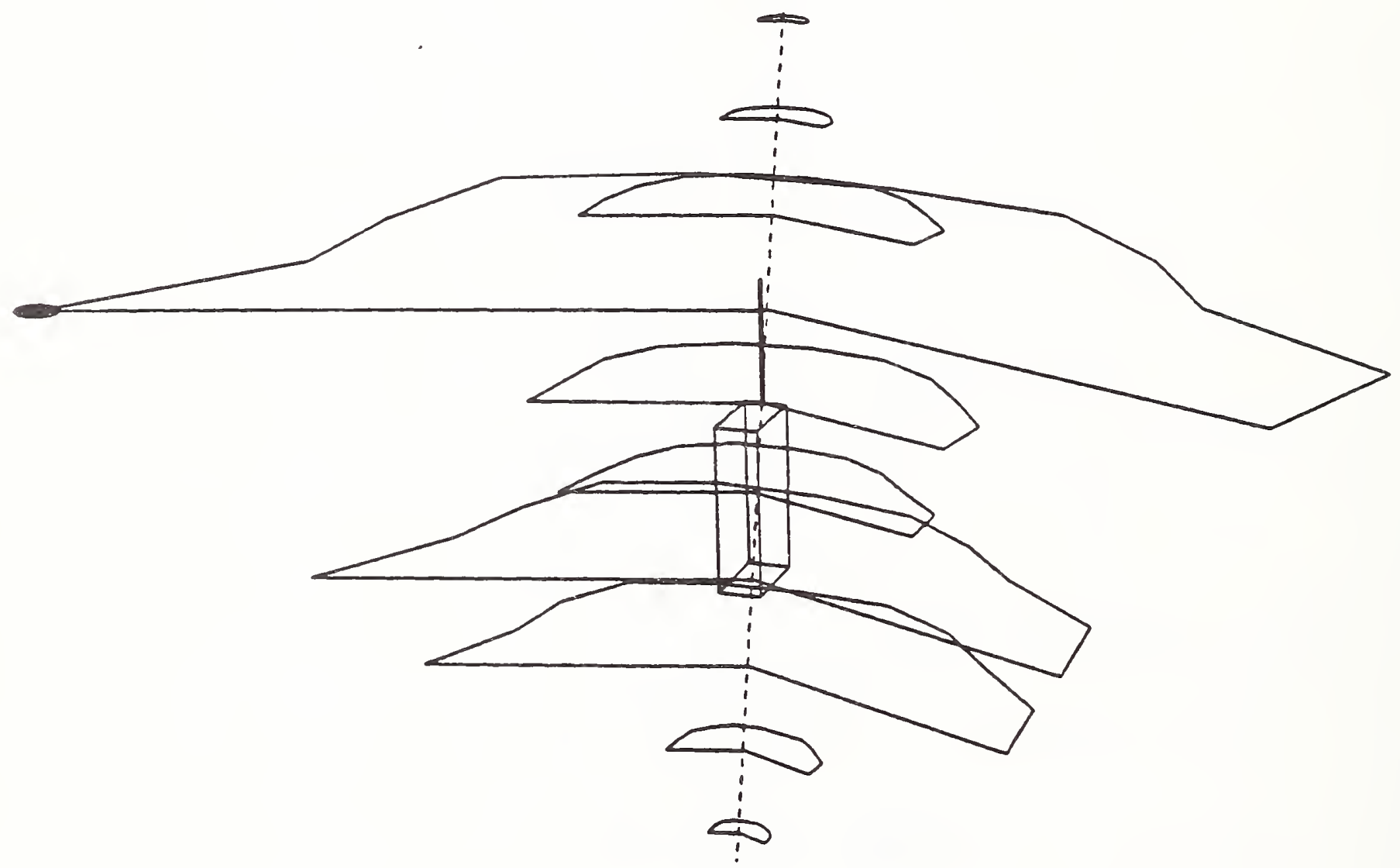

Figure 27. Three-dimensional plot of magnitude of electric field around transceiver $\mathrm{D} 40(40 \mathrm{MHz})$. Radii of disks are proportional to magnitude of electric field. Separation distance between transceiver antenna and probes is in centimeters (RADIUS $=7$ ). Maximum value of field strength is marked with black dot. The two numbers after MAXIMUM POINT are electric field strength in volts per meter and angle of rotation in degrees. 
D40

RADIUS $=12$

NUMBER OF POINTS $=16$

$=$ MAXIMUM POINI: $122.30 \quad 157.50$

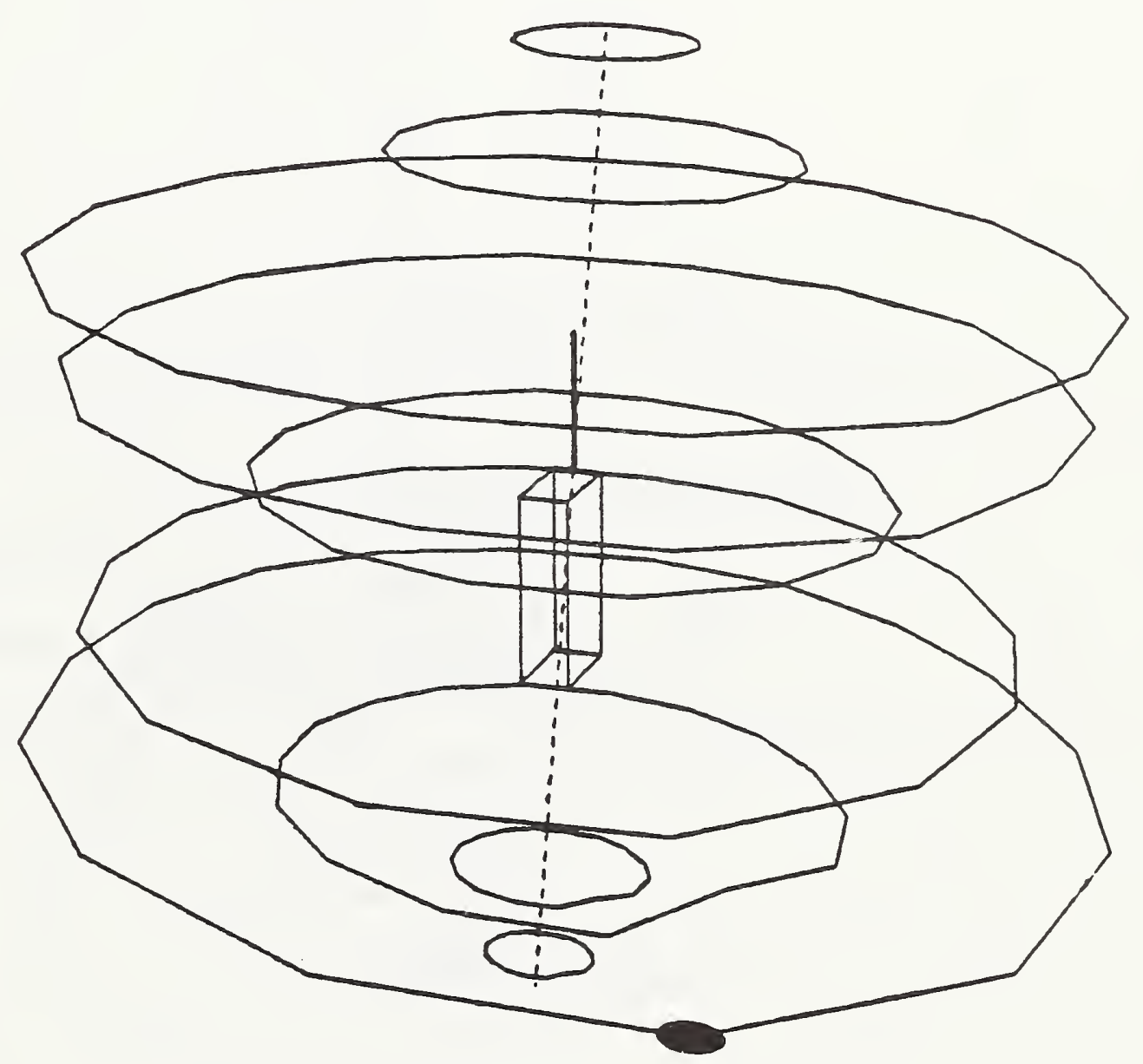

Figure 28. Three-dimensional plot of magnitude of electric field around transceiver D40 (40 MHz). Radii of disks are proportional to magnitude of electric field. Separation distance between transceiver antenna and probes is in centimeters (RADIUS $=12$ ). Maximum value of field strength is marked with black dot. The two numbers after MAXIMUM POINT are electric field strength in volts per meter and angle of rotation in degrees. 
E162

RADIUS $=7$

NUMBER OF POINTS $=16$

$O=$ MAXIMUM POINT: $566.61 \quad 112.50$

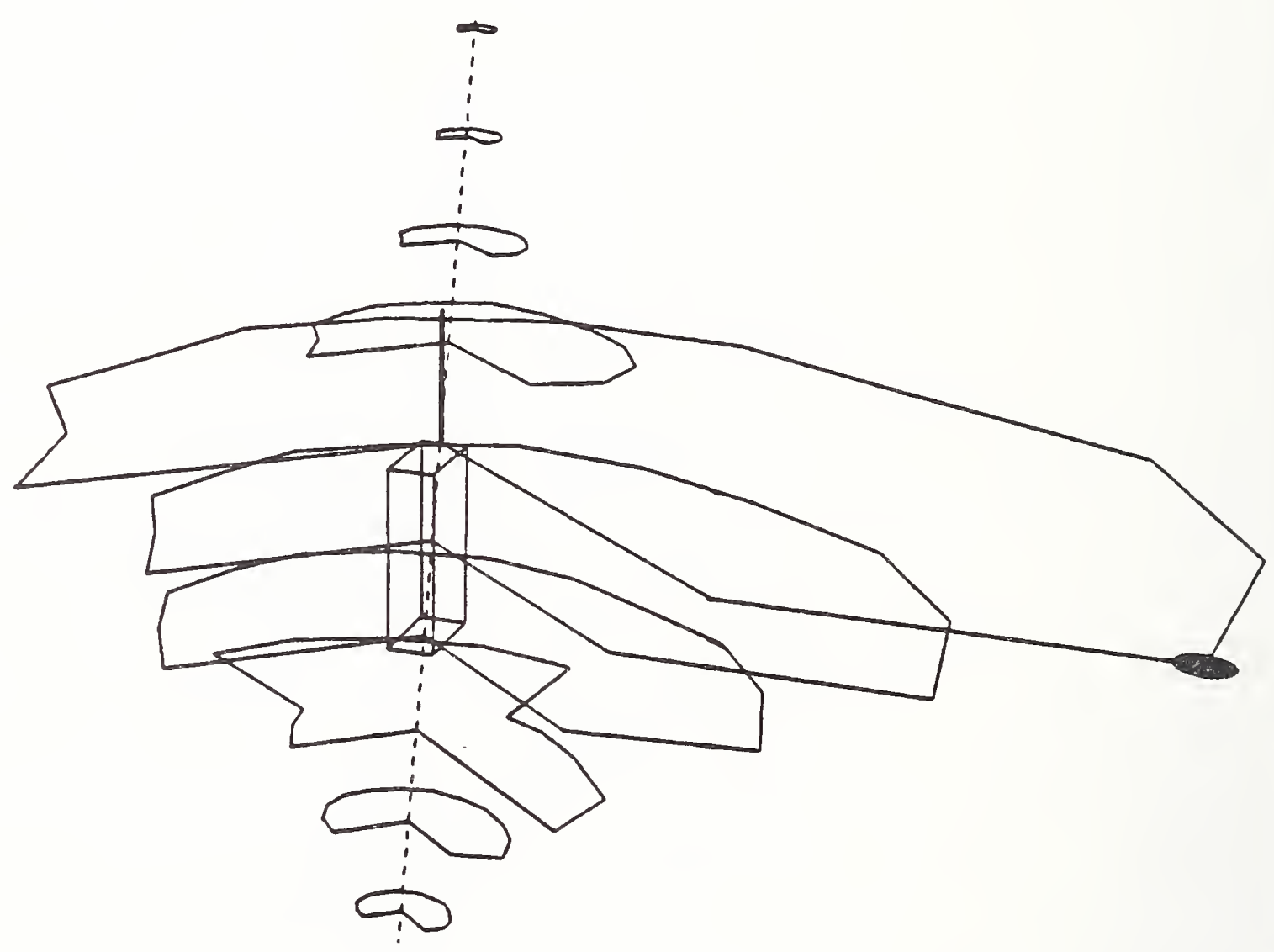

Figure 29. Three-dimensional plot of magnitude of electric field around transceiver E162 (162 MHz). Radii of disks are proportional to magnitude of electric field. Separation distance between transceiver antenna and probes is in centimeters (RADIUS $=7$ ). Maximun value of field strength is marked with black dot. The two numbers after MAXIMUM POINT are electric field strength in volts per meter and angle of rotation in degrees. 


\section{E162}

RRDIUS $=12$

NUMBER OF POINTS $=16$

- MAXIMUM POINT: $193.38 \quad 157.50$

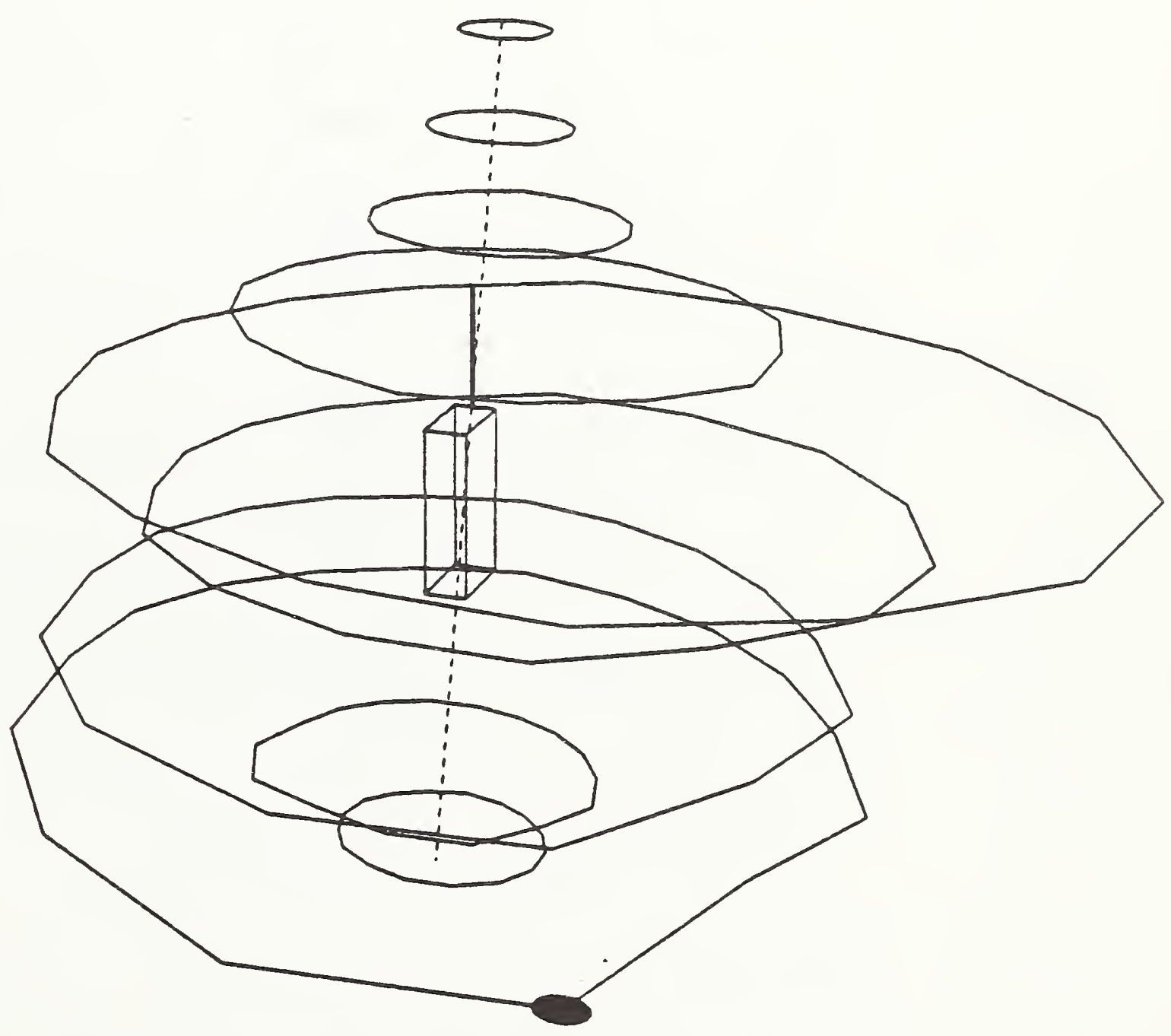

Figure 30. Three-dimensional plot of magnitude of electric field around transceiver E162 (162 MHz). Radii of disks are proportional to magnitude of electric field. Separation distance between transceiver antenna and probes is in centimeters (RADIUS $=12$ ). Maximum value of field strength is marked with black dot. The two numbers after MAXIMUM POINT are electric field strength in volts per meter and angle of rotation in degrees. 
0162

RADIUS $=7$

NUMBER OF POINTS $=16$

O MRXIMUM POINT: $880.30-112.50$

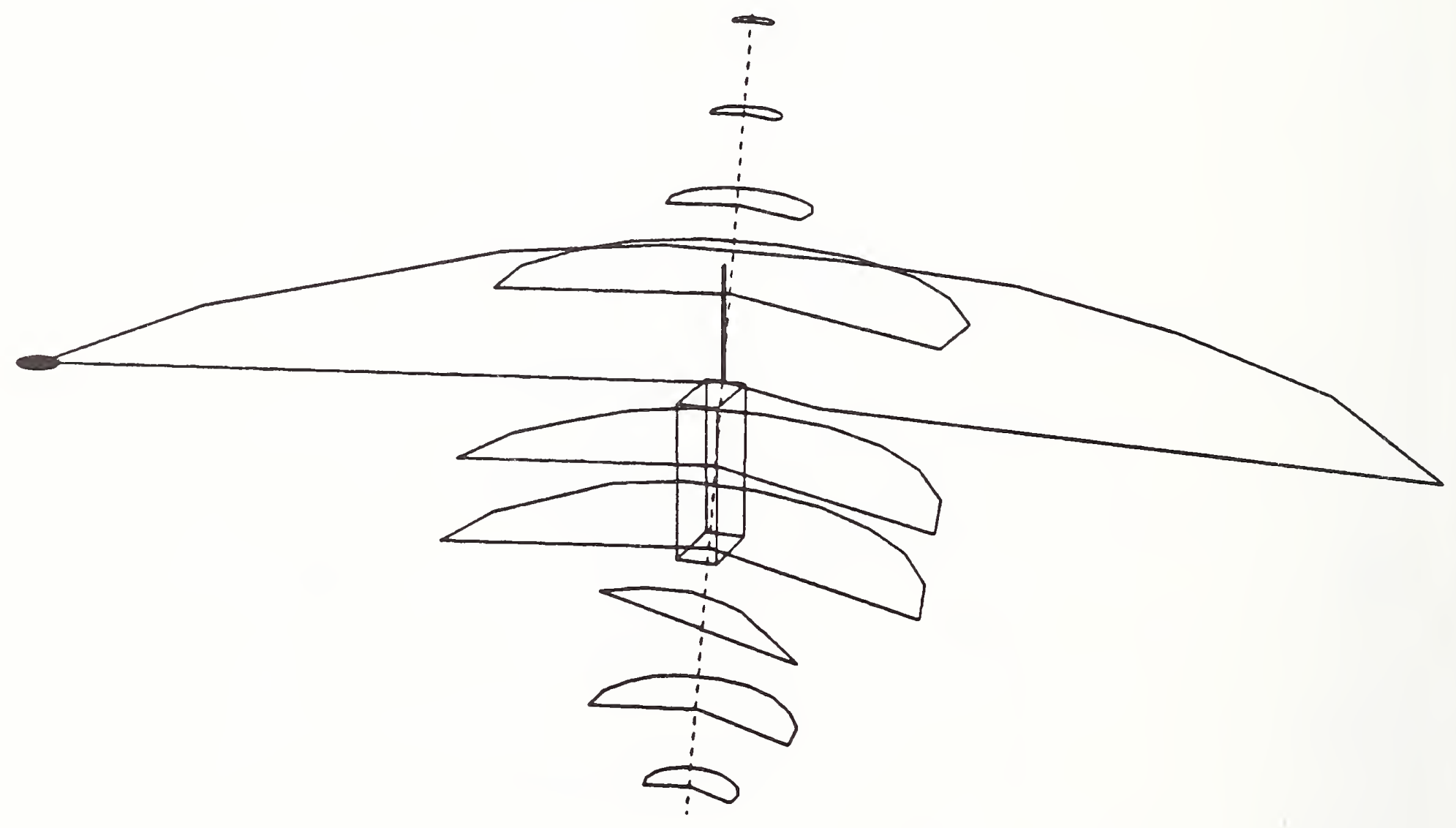

Figure 31. Three-dimensional plot of magnitude of electric field around transceiver D162 (162 MHz). Radii of disks are proportional to magnitude of electric field. Separation distance between transceiver antenna and probes is in centimeters (RADIUS $=7$ ). Maximum value of field strength is marked with black dot. The two numbers after MAXIMUM POINT are electric field strength in volts per meter and angle of rotation in degrees. 
D162

RADIUS $=12$

NUMBER OF POINTS $=16$

O MAXIMUM POINT: $266.10 \quad 157.50$

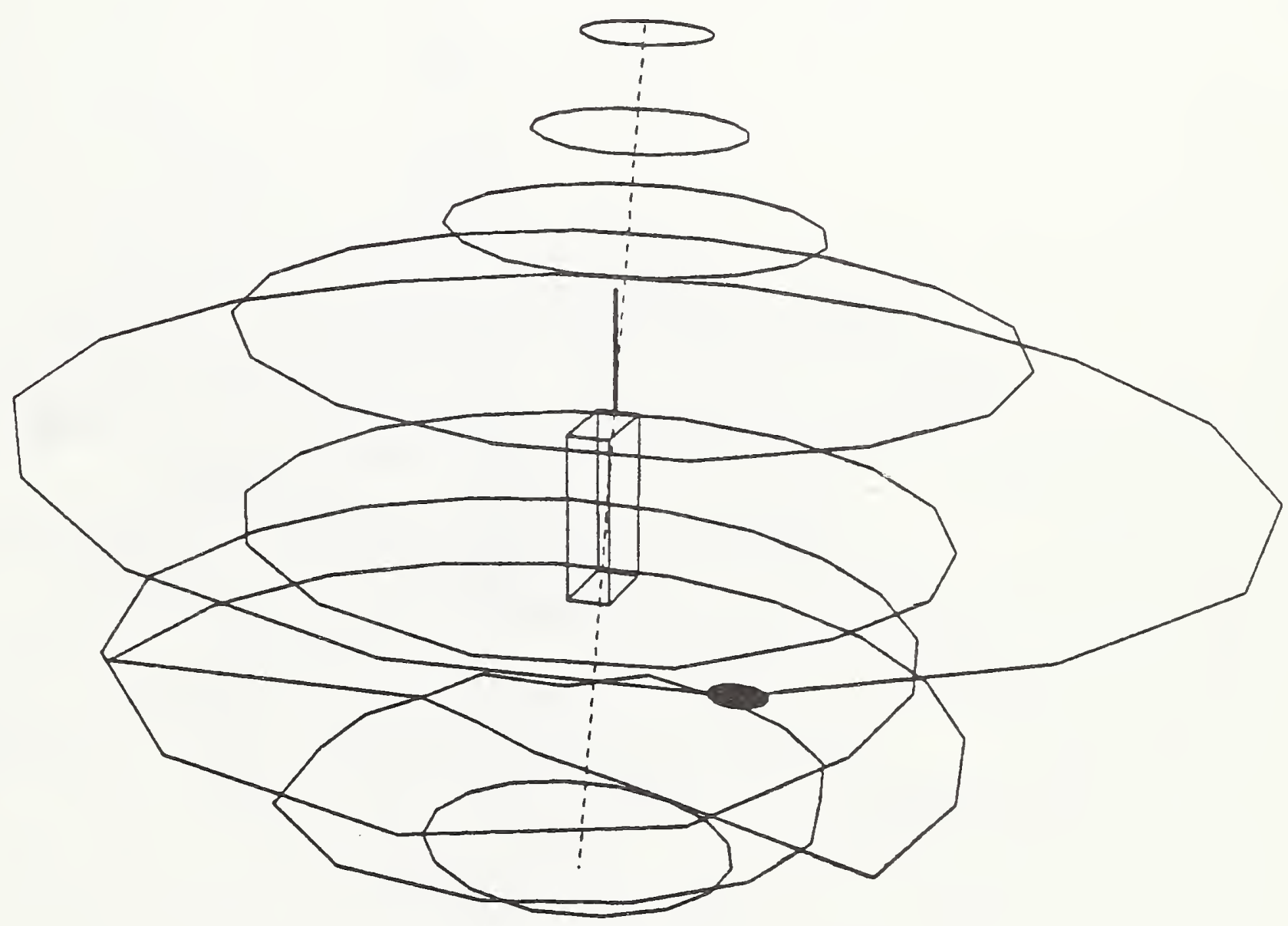

Figure 32. Three-dimensional plot of magnitude of electric field around transceiver D162 (162 MHz). Radii of disks are proportional to magnitude of electric field. Separation distance between transceiver antenna and probes is in centimeters (RADIUS $=12$ ). Maximum value of field strength is marked with black dot. The two numbers after MAXIMUM POINT are electric field strength in volts per meter and angle of rotation in degrees. 
C464

RADIUS $=7$

NUMBER OF POINTS $=100$

$=$ MRXIMUM POINT: $297.11 \quad 104.40$

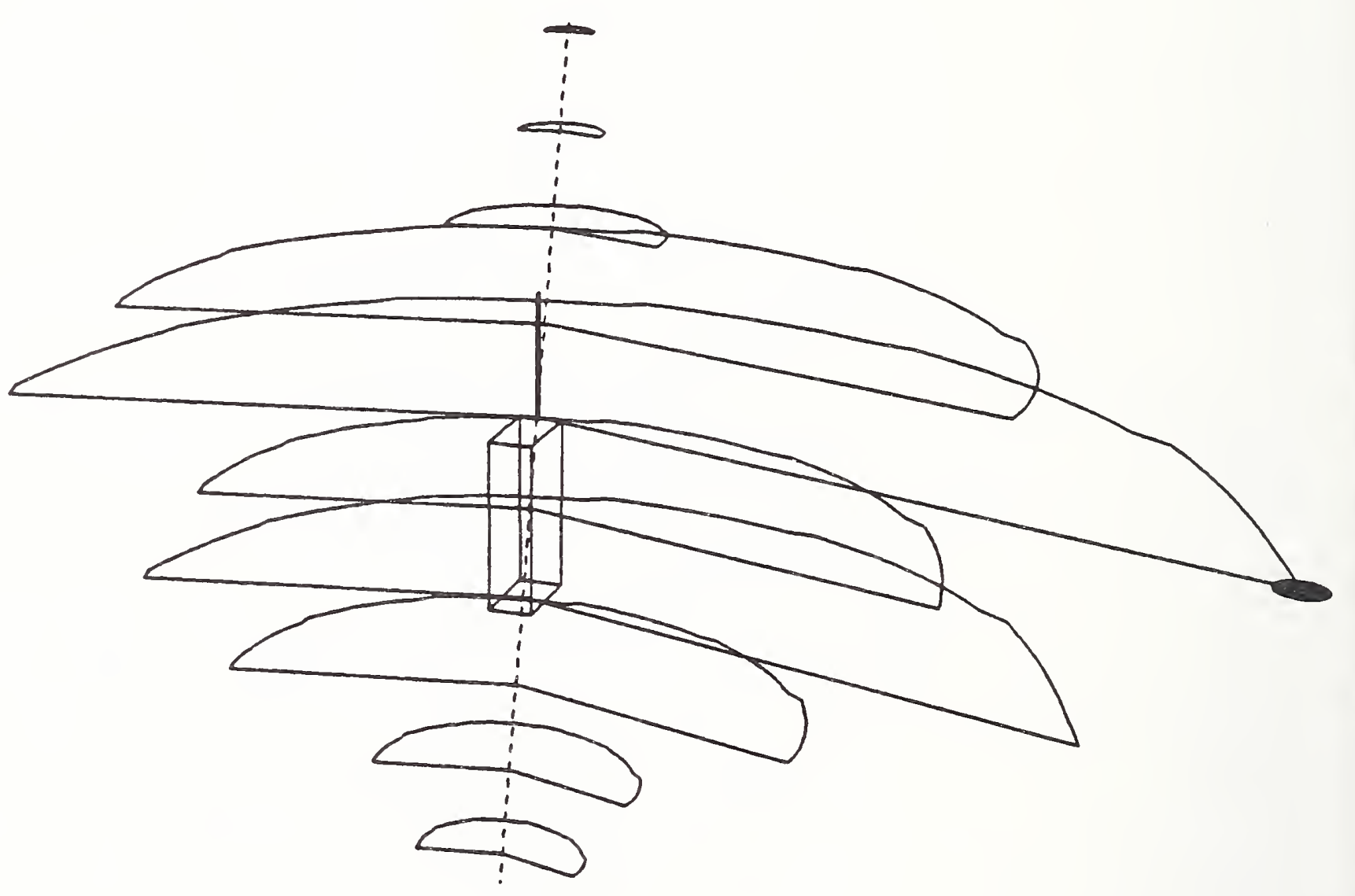

Figure 33. Three-dimensional plot of magnitude of electric field around transceiver $C 464(464 \mathrm{MHz})$. Radii of disks are proportional to magnitude of electric field. Separation distance between transceiver antenna and probes is in centimeters (RADIUS $=7$ ). Maximum value of field strength is marked with black dot. The two numbers after MAXIMUM POINT are electric field strength in volts per meter and angle of rotation in degrees. 


\section{C464}

RADIUS $=12$

NUMBER OF POINTS $=50$

$=$ MAXIMUM POINT: 179.84144 .00

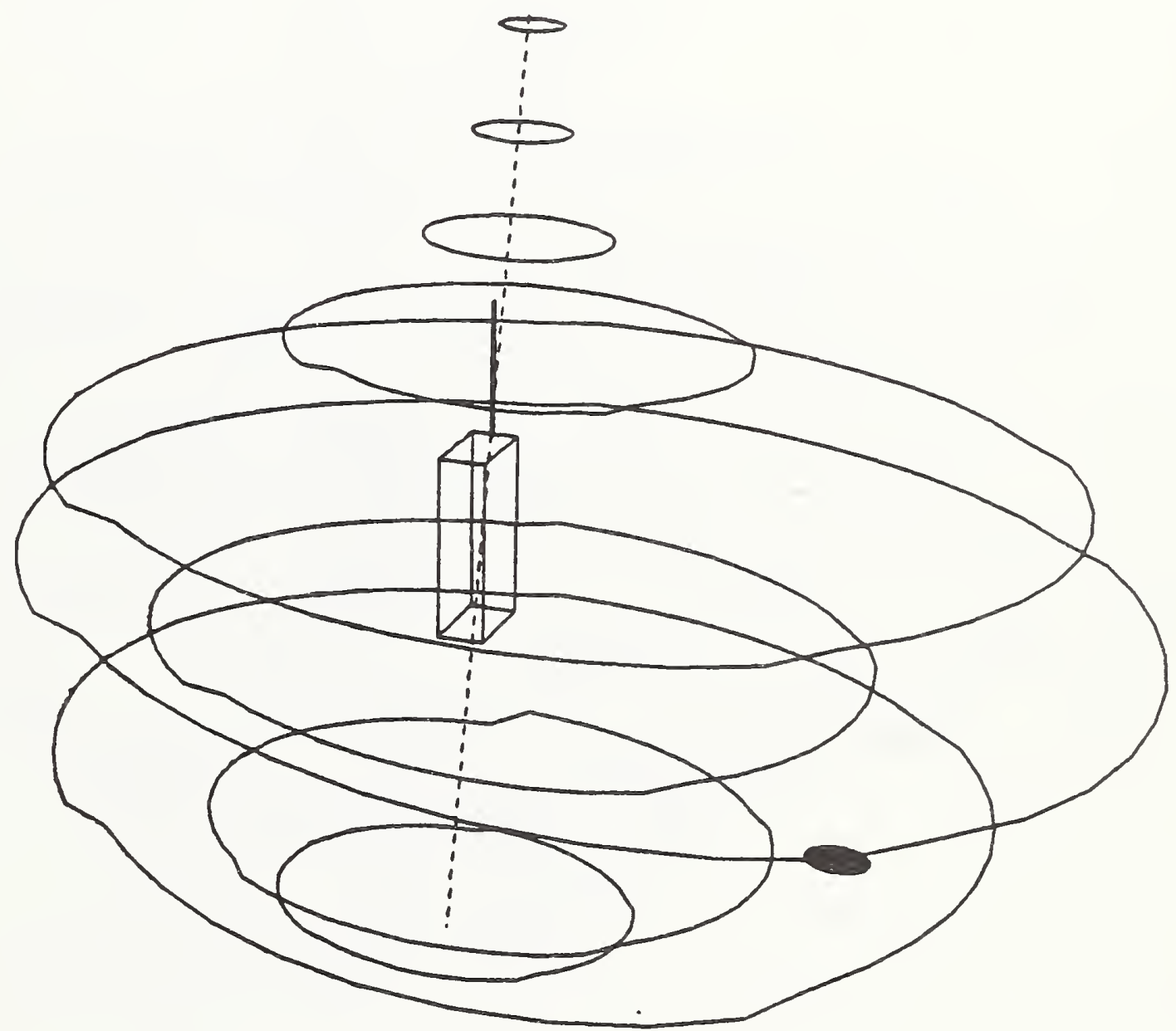

Figure 34. Three-dimensional plot of magnitude of electric field around transceiver 6464 (464 MHz). Radii of disks are proportional to magnitude of electric field. Separation distance between transceiver antenna and probes is in centimeters (RADIUS = 12). Maximum value of field strength is marked with black dot. The two numbers after MAXIMUM POINT are electric field strength in volts per'meter and angle of rotation in degrees. 
C464G

RADIUS $=12$

NUMBER OF POINTS $=16$

$=$ MAXIMUM POINT: $148.53-157.50$

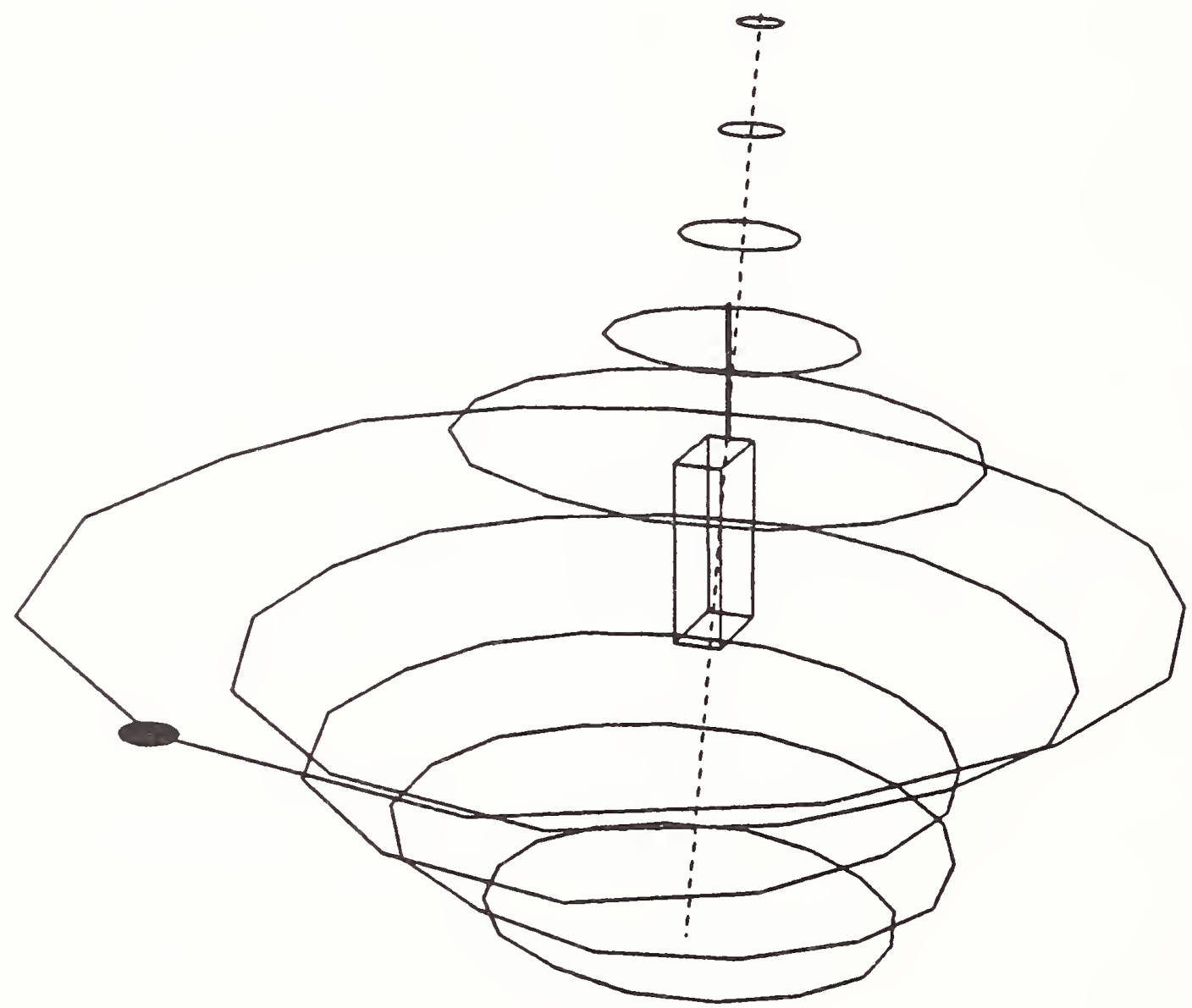

Figure 35. Three-dimensional plot of magnitude of electric field around transceiver 6464 (464 MHz) measured on ground screen - compare with figure 28 which was measured in anechoic chamber. Radii of disks are proportional to magnitude of electric field. Separation distance between transceiver antenna and probes is in centimeters (RADIUS $=12$ ). Maximum value of field strength is marked with black dot. The two numbers after MAXIMUM POINT are electric field strength in volts per meter and angle of rotation in degrees. 


\section{B464}

RADIUS $=7$

NUMBER OF POINTS $=100$

- MAXIMUM POINT: $158.82 \quad 104.40$

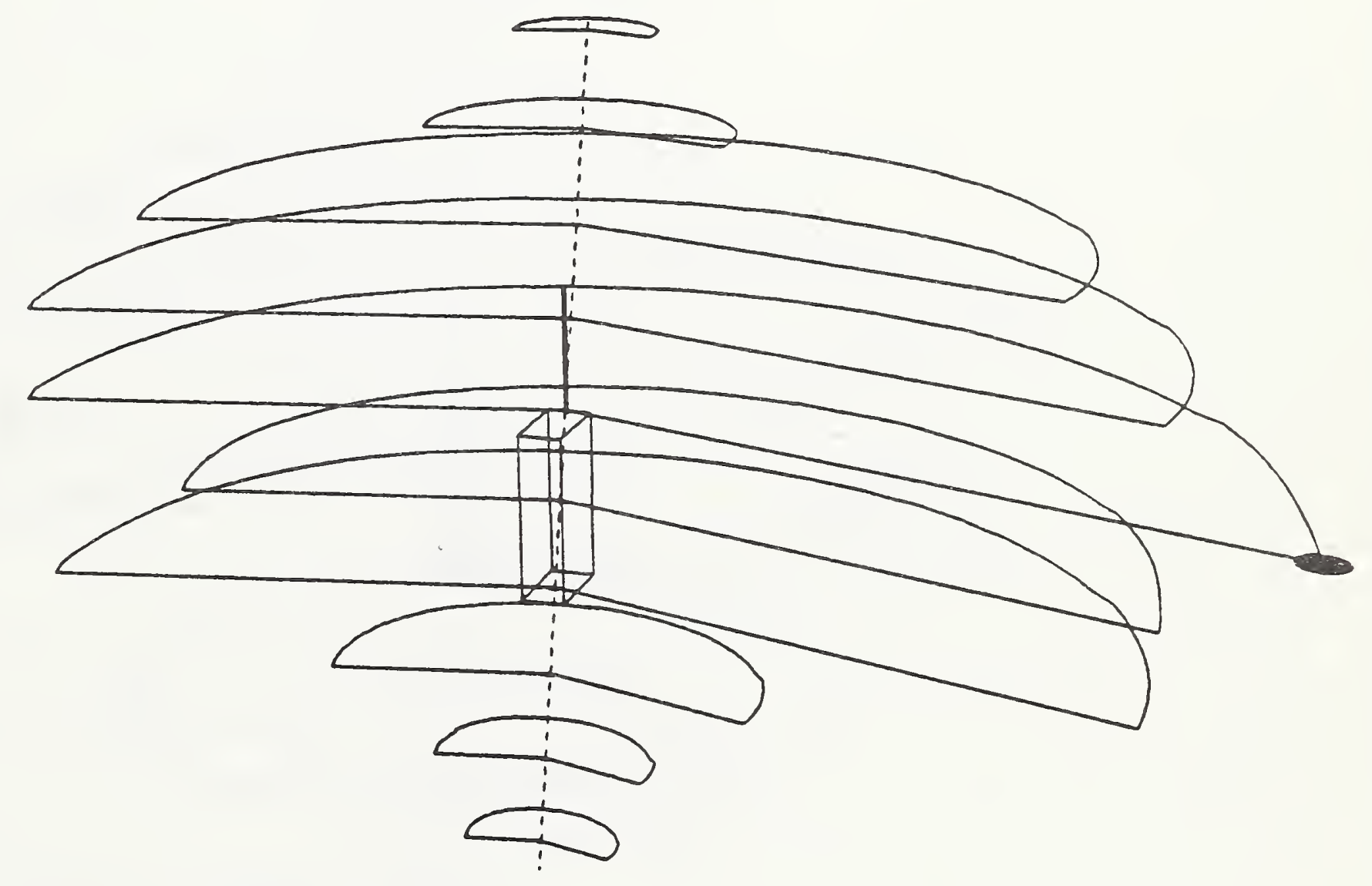

Figure 36. Three-dimensional plot of magnitude of electric field around transceiver $\mathrm{B} 464(464 \mathrm{MHz})$. Radii of disks are proportional to magnitude of electric field. Separation distance between transceiver antenna and probes is in centimeters (RADIUS $=7$ ). Maximum value of field strength is marked with black dot. The two numbers after MAXIMUM POINT are electric field strength in volts per meter and angle of rotation in degrees. 


\section{B464}

RADIUS $=12$

NUMBER OF POINTS $=50$

= MAXIMUM POINT: $82.22 \quad 151.20$

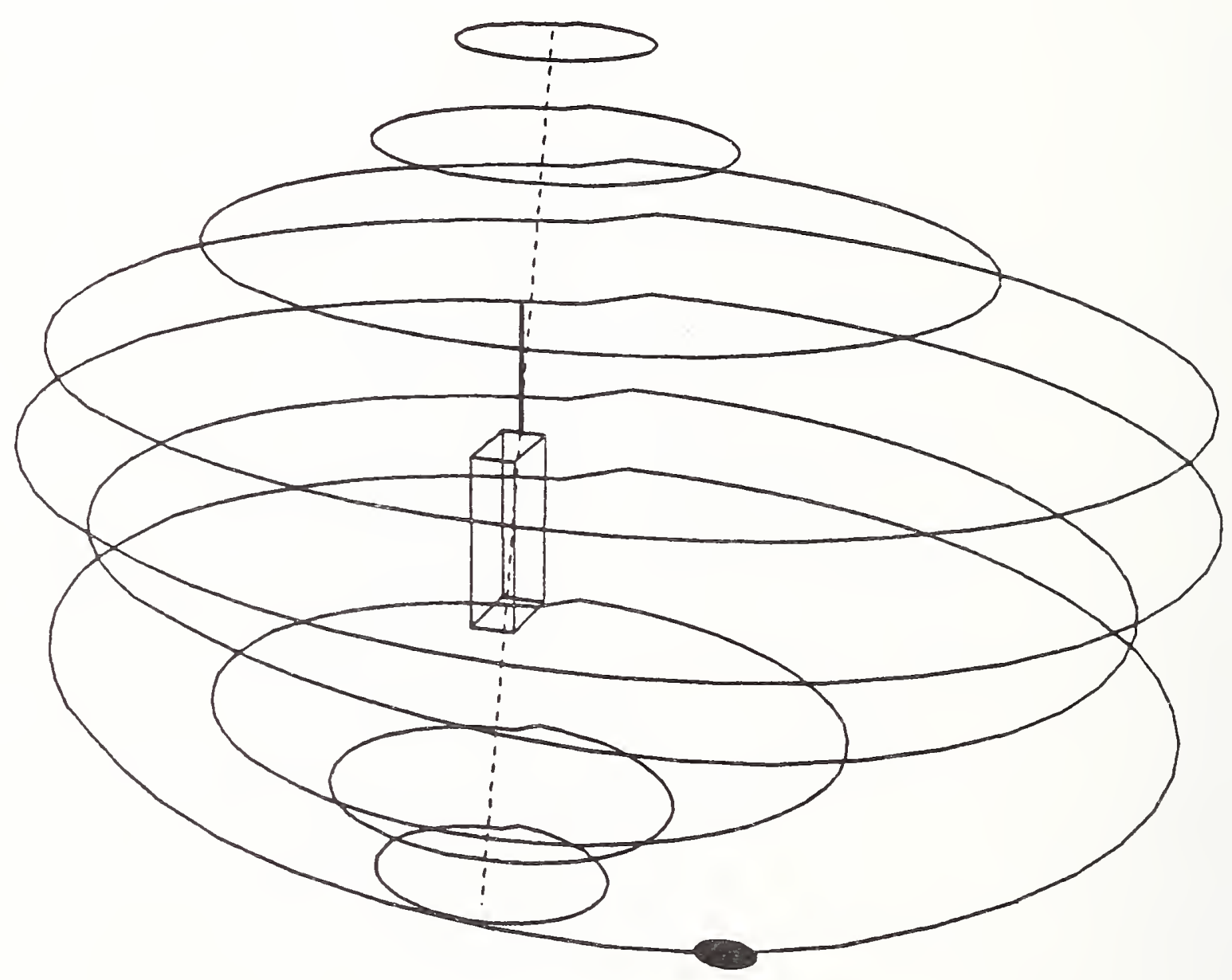

Figure 37. Three-dimensional plot of magnitude of electric field around transceiver $B 464(464 \mathrm{MHz})$. Radii of disks are proportional to magnitude of electric field. Separation distance between transceiver antenna and probes is in centimeters (RADIUS $=12$ ). Maximum value of field strength is marked with black dot. The two numbers after MAXIMUM POINT are electric field strength in volts per meter and angle of rotation in degrees. 
A823

RADIUS $=7$

NUMBER OF POINTS $=100$

= MAXIMUM POINT: $88.96-108.00$

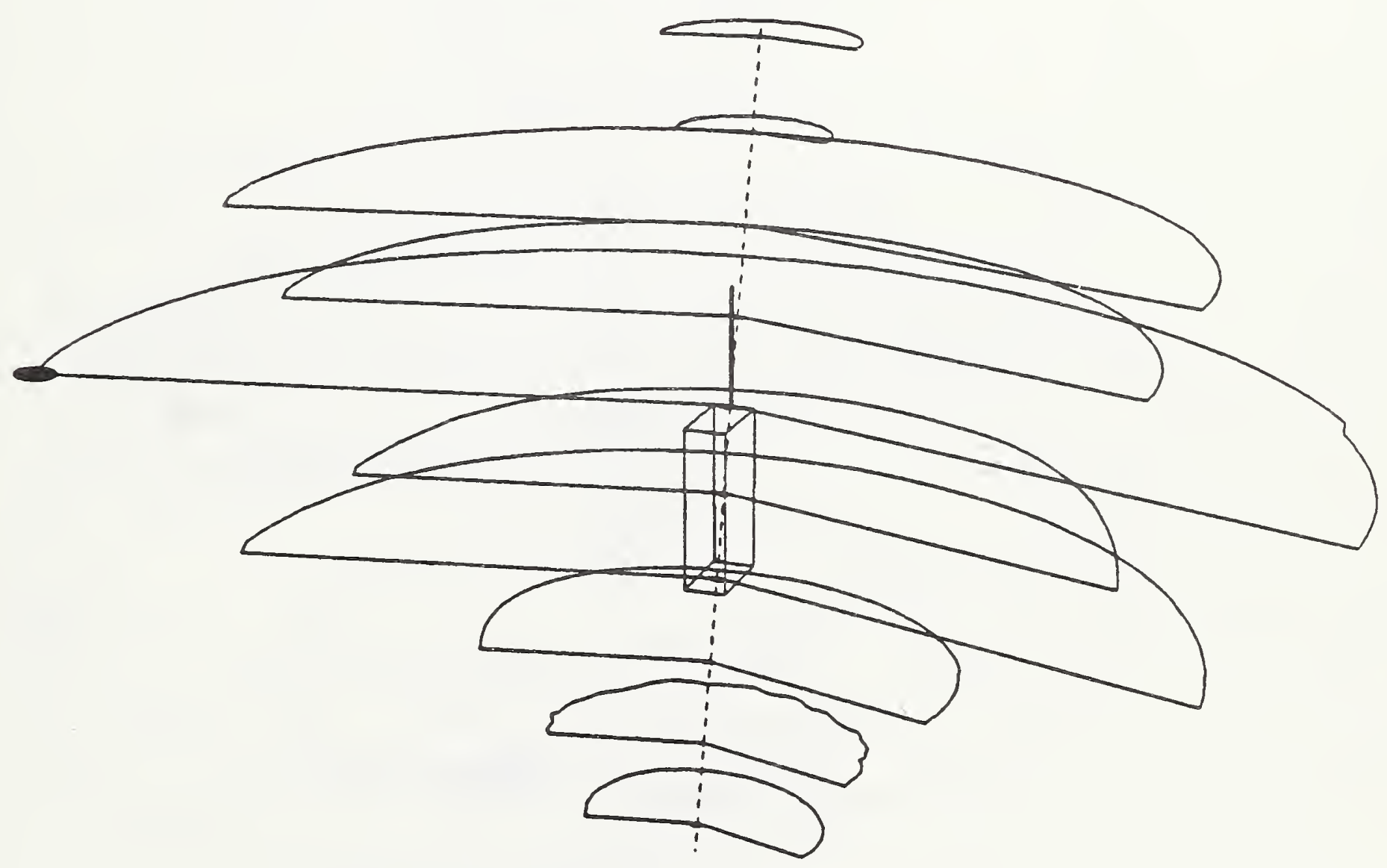

Figure 38. Three-dimensional plot of magnitude of electric field around transceiver A823 (823 $\mathrm{MHz})$. Radii of disks are proportional to magnitude of electric field. Separation distance between transceiver antenna and probes is in centimeters (RADIUS $=7$ ). Maximum value of field strength is marked with black dot. The two numbers after MAXIMUM POINT are electric field strength in volts per meter and angle of rotation in degrees. 
A823

RRDIUS $=12$

NUMBER OF POINTS $=50$

$=$ MAXIMUM POINT: $56.70 \quad 158.40$

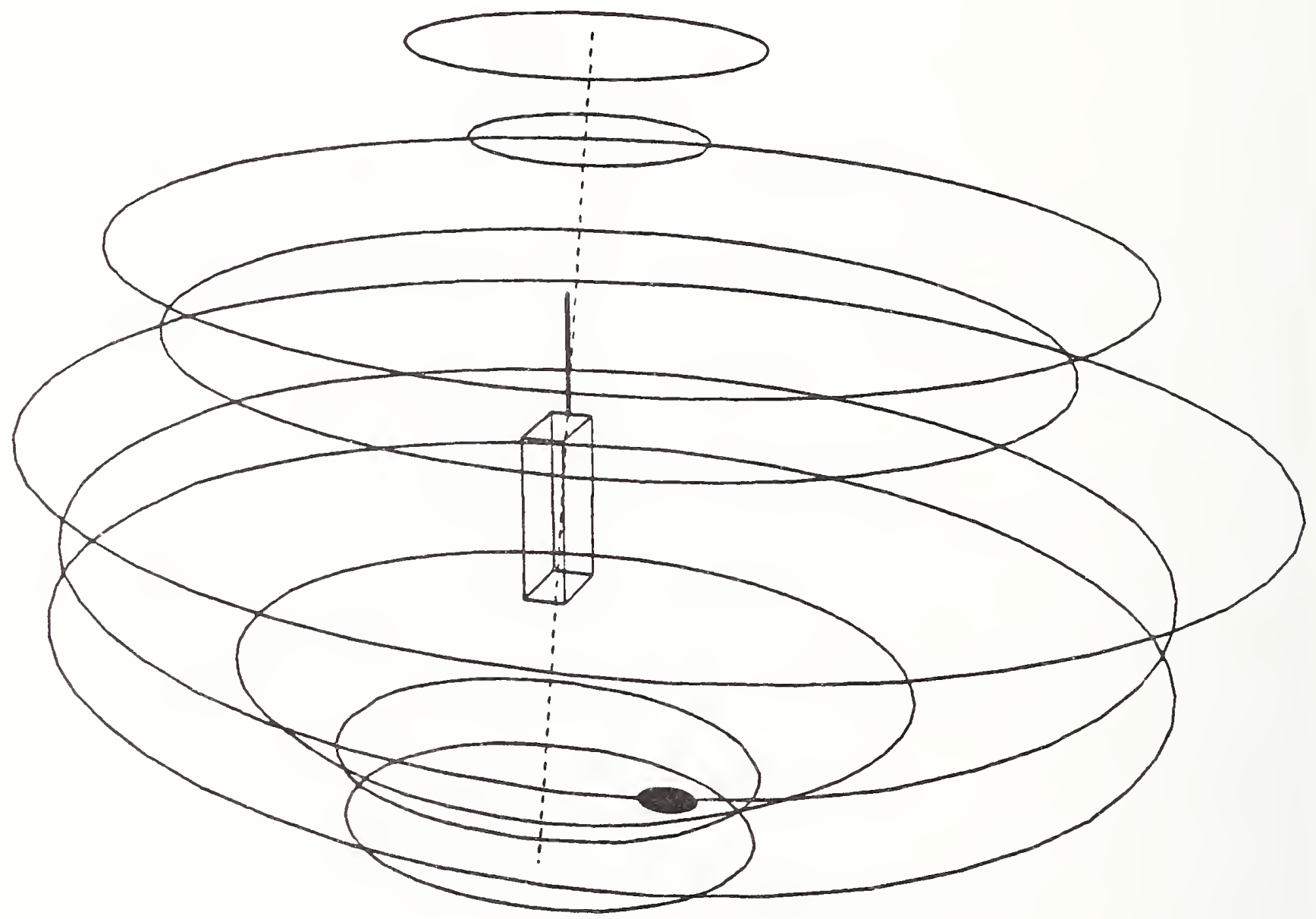

Figure 39. Three-dimensional plot of magnitude of electric field around transceiver A823 (823 $\mathrm{MHz})$. Radii of disks are proportional to magnitude of electric field. Separation distance between transceiver antenna and probes is in centimeters (RADIUS $=12$ ). Maximum value of field strength is marked with black dot. The two numbers after MAXIMUM POINT are electric field strength in volts per meter and angle of rotation in degrees. 


\section{B823}

RADIUS $=7$

NUMBER OF POINTS $=100$

= MAXIMUM POINT: $157.69-28.80$

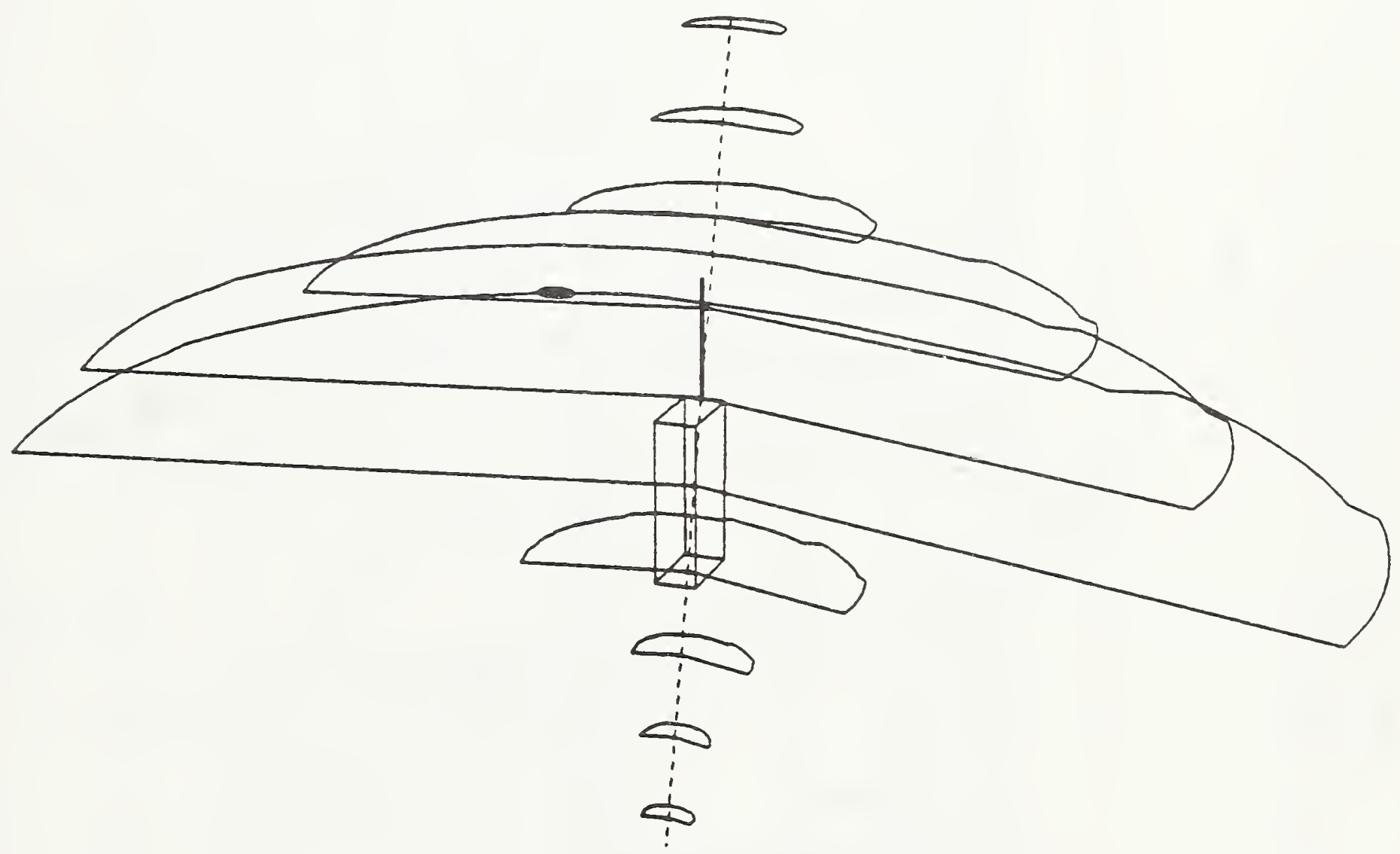

Figure 40. Three-dimensional plot of magnitude of electric field around transceiver B823 (823 MHz). Radii of disks are proportional to magnitude of electric field. Separation distance between transceiver antenna and probes is in centimeters (RADIUS $=7$ ). Maximum value of field strength is marked with black dot. The two numbers after MAXIMUM POINT are electric field strength in volts per meter and angle of rotation in degrees. 
$B 823$

RADIUS $=12$

NUMBER OF POINTS $=50$

$=$ MAXIMUM POINT: $95.00 \quad 72.00$

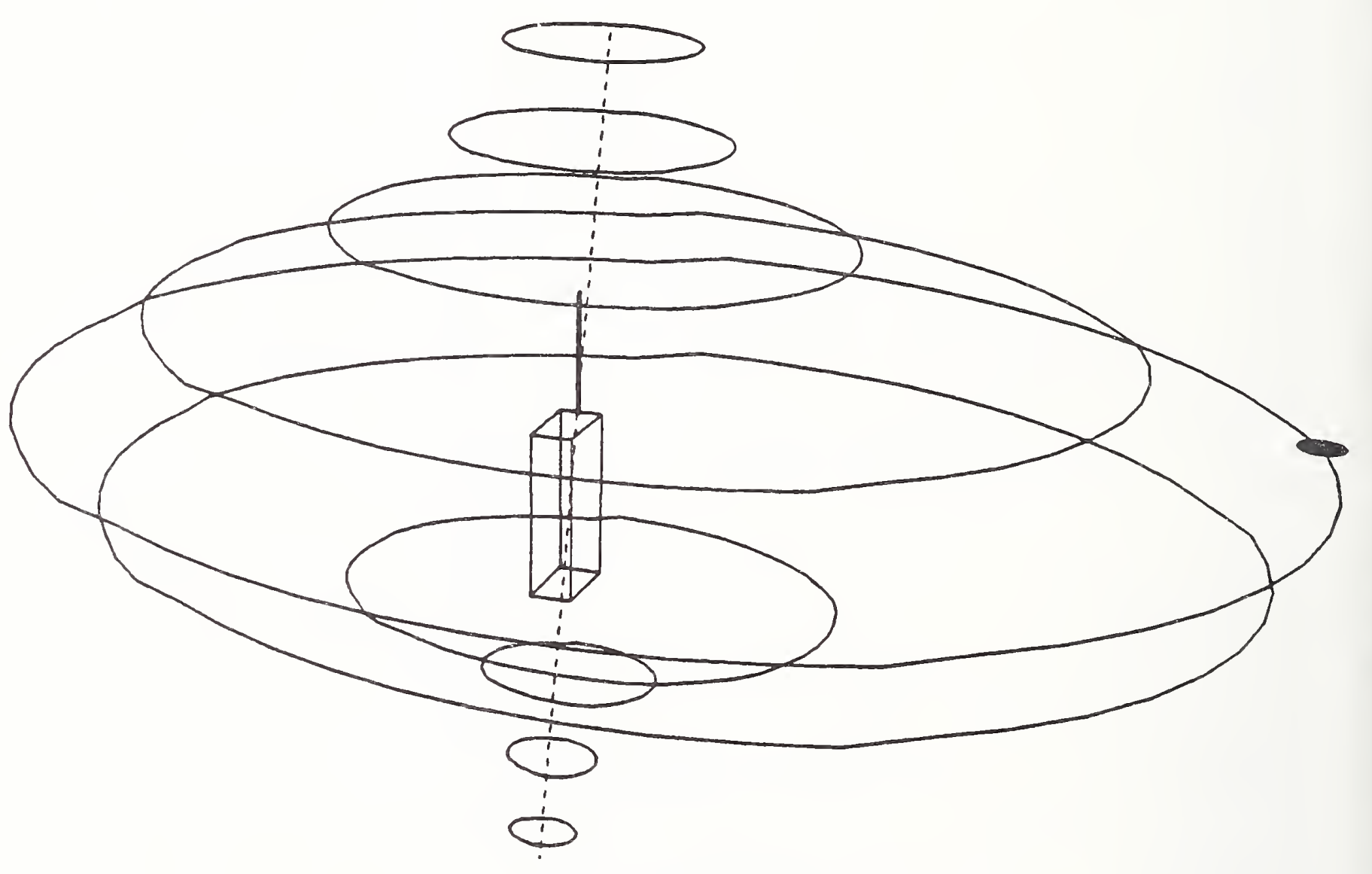

Figure 41. Three-dimensional plot of magnitude of electric field around transceiver 3823 (823 MHz). Radii of disks are proportional to magnitude of electric field. Separation distance between transceiver antenna and probes is in centimeters (RADIUS $=12$ ). Maximum value of field strength is marked with black dot. The two numbers after MAXIMUM POINT are electric field strength in volts per meter and angle of rotation in degrees. 


\section{要 $\frac{0}{2}$}

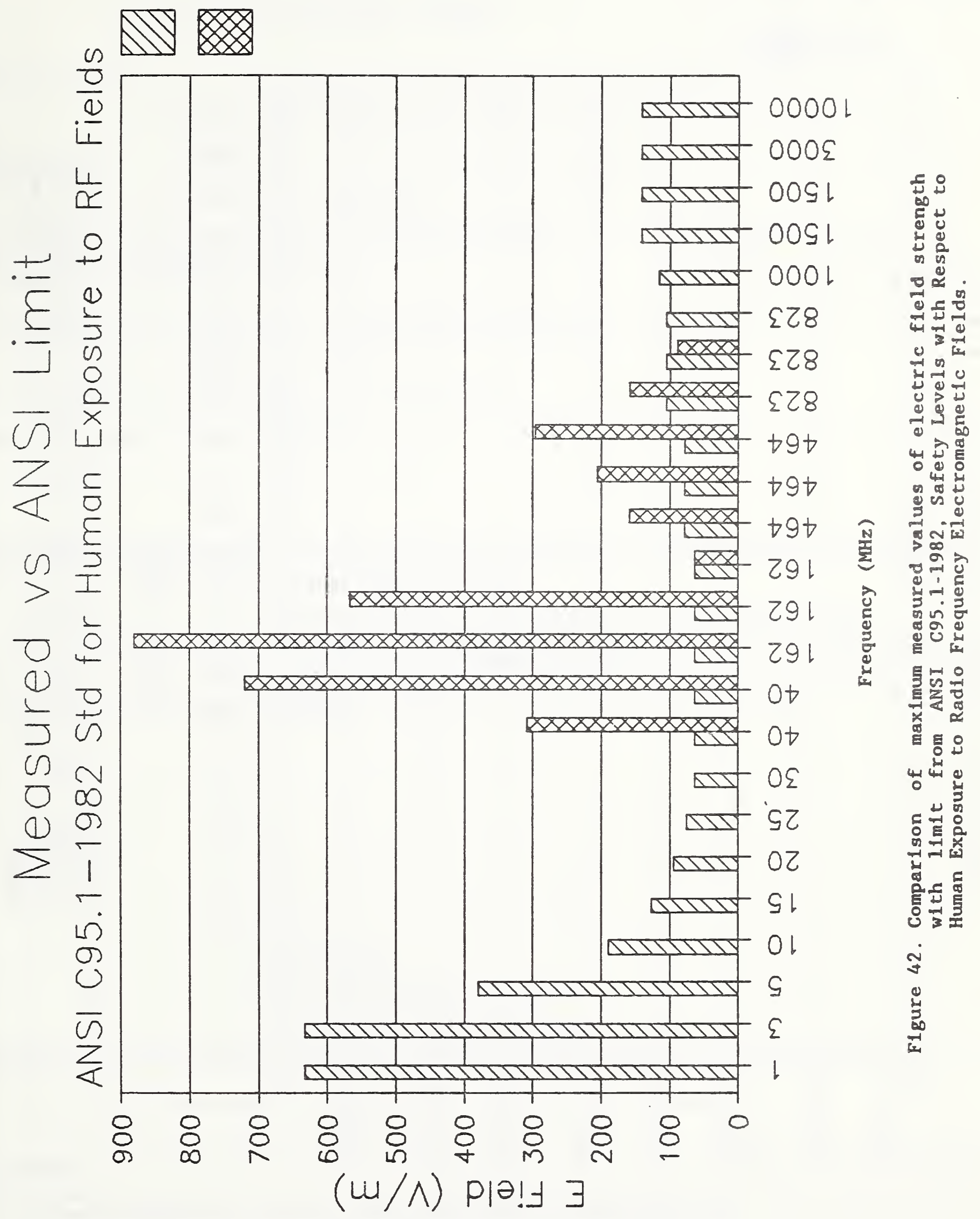


要 $\frac{0}{2}$

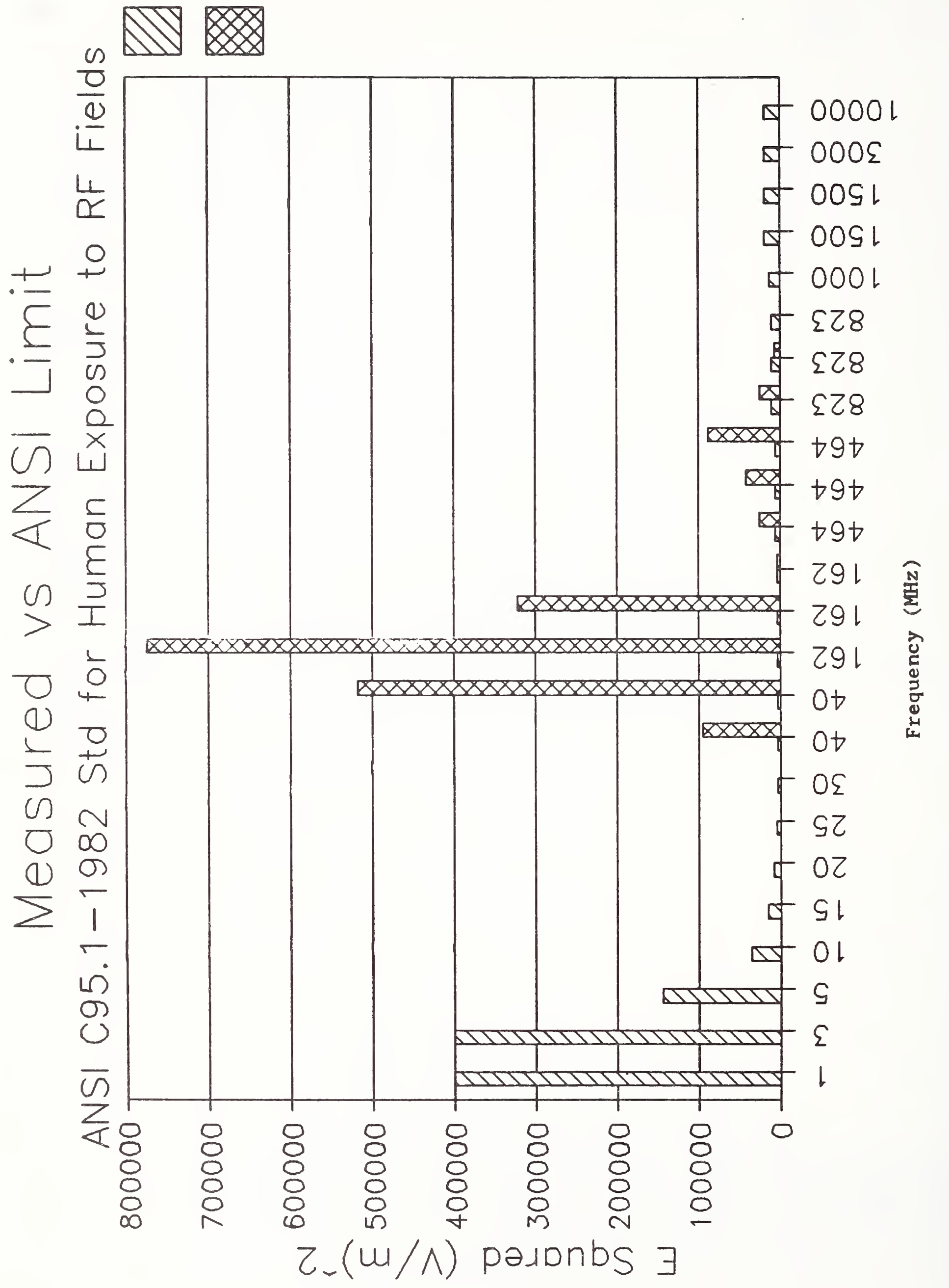

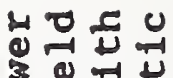

更事

잉

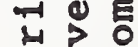

出造

正

1.

잉

on

胥.

a a

- चृ

ه

भुे

घ

4 氞氞。

。

$\underbrace{}_{4 \rightarrow 1}$

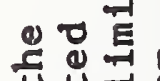

幽

43 돈

氙。

ㄷํㅇ

令各出

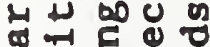

o. व a

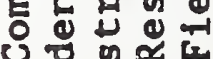

学

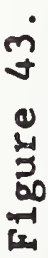


$\begin{array}{ll}\text { BL-114A } & \text { U.S. DEPARTMENT OF COMMERCE } \\ (5-90) & \text { NATIONAL INSTITUTE OF STANDARDS AND TECHNOLOGY }\end{array}$ BIBLIOGRAPHIC DATA SHEET
1. PUBLICATION OR REPORT MUMBER

NISTIR 90-3938

2. PERFORMING ORGANIZATION REPORT NUMEER

3. PUBLICATION DATE

May 1990

4. TITLE AND SUBTITLE

Measurement of Electric Field Strength Near Higher Powered Personal Transceivers

5. AUTHOA(S)

John Adams, Doris Wu, and Alan Budlong

6. PERFORMING ORGANIZATION (IF JOINT OR OTHER THAN NIST, SEE INSTRUCTIONS)

U.S. DEPARTMENT OF COMMERCE

NATIONAL INSTITUTE OF STANDARDS AND TECHNOLOGY

BOULDER, COLORADO $80303-3328$

7. CONTRACT/GRANT NUMBER

8. TYPE OF REPORT AND PERIOD COVERED

9. SPONSORINQ ORGANIZATION NAME AND COMPLETE ADDRESS (STREET, CITY, STATE, ZIP)

Law Enforcement Standards Laboratory

National Institute of Standards and Technology

Gaithersburg, Maryland 20899

10. SUPPLEMENTARY NOTES

11. ABSTRACT (A 200-WORD OR LESS FACTUAL SUMMARY OF MOST SIGNIFICANT INFORMATION. IF DOCUMENT INCLUDES A SIGNIFICANT BIBUIOGRAPHY OR UTERATURE SURVEY, MENTION IT HERE.)

Electric field strengths were measured at a number of points near 5-W personal transceivers. The points were located on cylinders of revolution around the antenna with radii of 7 , 9.5, $12,14.5,17$, and, in some cases, 27, 37, and $47 \mathrm{~cm}$. At shorter distances, these measured values exceeded the exposure limits suggested in ANSI Standard C95.1-1982.

12. KEY WORDS (6 TO 12 ENTRIES; ALPHABETICAL ORDER; CAPITALZE ONLY PROPER NAMES; AND SEPARATE KEY WORDS BY SEMICOLONS)

electric field measurements; personal transceivers; walkie-talkies

13. AVAILABIUTY

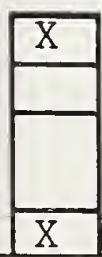

UNUMITED

FOR OFFICIAL DISTRIBUTION. DO NOT RELEASE TO NATIONAL TECHNICAL INFORMATION SERVICE (NTIS).

ORDER FROM SUPERINTENDENT OF DOCUMENTS, U.S. GOVERNMENT PRINTING OFFICE, WASHINGTON, DC 20402.

ORDER FROM NATIONAL TECHNICAL INFORMATION SERVICE (NTIS), SPRINGFIELD, VA 22161.
14. NUMBER OF PAINTED PAGES

$$
60
$$



